Discussion Paper No. 07-015

\title{
Age-dependent Skill Formation and Returns to Education
}

Friedhelm Pfeiffer and Karsten Reuß

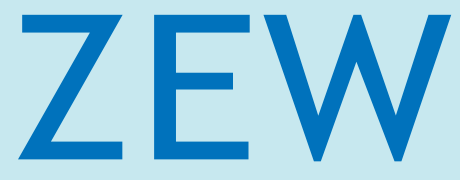

Zentrum für Europäische Wirtschaftsforschung $\mathrm{GmbH}$

Centre for European

Economic Research 


\title{
Discussion Paper No. 07-015 \\ Age-dependent Skill Formation and Returns to Education
}

\author{
Friedhelm Pfeiffer and Karsten Reuß
}

Download this ZEW Discussion Paper from our ftp server:

ftp://ftp.zew.de/pub/zew-docs/dp/dp07015.pdf

Die Discussion Papers dienen einer möglichst schnellen Verbreitung von neueren Forschungsarbeiten des ZEW. Die Beiträge liegen in alleiniger Verantwortung der Autoren und stellen nicht notwendigerweise die Meinung des ZEW dar.

Discussion Papers are intended to make results of ZEW research promptly available to other economists in order to encourage discussion and suggestions for revisions. The authors are solely responsible for the contents which do not necessarily represent the opinion of the ZEW. 


\section{Non technical summary}

In this study, we try to connect the economic literature on human capital formation with the biological and psychological literature on early childhood development and self-regulation. Our basic framework for assessing the distribution of age-specific returns to investment in skills is an elaboration of the model of skill formation from Cunha, Heckman et al. (2006) over the life cycle. We illustrate the cumulative and synergetic nature of skill formation in a framework where learning abilities differ with respect to age and may differ between individuals and where individuals face heterogeneous environments. Student achievement scores and human capital are modelled explicitly as a function of cognitive and self-regulatory skills. Institutional aspects of labour markets which may shape the distribution of human capital are taken into account in the simulation model.

The impact of educational polices which aim at enhancing skills is evaluated in terms of their longer run multiplier effects. Various age- and skill-specific investment strategies are appreciated with respect to individual returns to education, with respect to the overall human capital of the population as well as with respect to its allocation among the members of society. Individual educational choices are investigated for tertiary investments to maximize human capital, while for preschool, primary and secondary education the impact of different investment strategies are assessed without a particular model of choice. The parameters of the simulation model are adjusted in a way such that the formation of intelligence and self-regulation across the life span in our population reproduces facts and stylized facts from the development of cognitive and self-regulatory skills, the student reading achievement scores from PISA 2000 and the inequality of wages in Germany in 2004.

Our simulation based evidence illustrates the shaping role early childhood has for human capital formation, growth and inequality. Skills beget skills and early investment has higher returns than later ones. Differences in individual giftedness have a higher impact on inequality of skills and human capital than differences stemming from the environment. A reasonable strategy for fostering human capital is to supply children with symmetric impulses into cognitive and self-regulatory skills until they reach adolescence. In adult age, however, more investments should be directed to improve self-regulatory skills. If it is not possible to invest in early childhood for whatever reasons, increased life expectancy seems to enhance the returns of tertiary education specifically for students from more disadvantaged environments. The relative gains from tertiary instead of primary additional education seem to be the higher the longer life expectancy lasts. In future research, improved longitudinal and cross-section data, both experimental and non-experimental, could be collected to upgrade the empirical understanding of the cumulative and synergetic nature of skill formation and the way families, schools and policies shape the future workforce. 


\title{
Age-dependent Skill Formation and Returns to Education
}

\author{
Friedhelm Pfeiffer** and Karsten Reuß* \\ *ZEW Mannheim \\ ** ZEW Mannheim, University of Mannheim
}

\begin{abstract}
:
In this study, we try to connect the economic literature on human capital formation with findings from neurobiology and psychology on early childhood development and self-regulation. Our basic framework for assessing the distribution of agespecific returns to investment in skills is an elaboration of the model of skill formation from Cunha, Heckman et al. (2006) over the life cycle. Our simulation based evidence illustrates the cumulative and synergetic nature of skill formation, the skill multiplier and the shaping role early childhood has for human capital formation, growth and inequality.
\end{abstract}

Keywords:

Intelligence, self-regulation, human capital, returns to education, life span.

JEL-classification: J21, J24, J31

Corresponding author:

Friedhelm Pfeiffer, Centre for European Economic Research, P.O. Box 103443, D-68034 Mannheim. Tel.: +49-621-1235-150, E-mail: pfeiffer@zew.de

\section{Acknowledgements:}

Friedhelm Pfeiffer acknowledges financial support form the German Science Foundation under grants PF 331/2 ("Microeconometric Methods to Assess Heterogeneous Returns to Education") and PF 331/3 ("Wages, Rent-Sharing and Collective Wage Bargaining") and from the ZEW "Förderkreis". We would like to thank Anja Achtziger, Gunhild Berg, Kathrin Göggel, Michael Gebel, Peter Gollwitzer, Christian Pfeifer, Winfried Pohlmeier and Manfred Laucht and seminar participants at the IAB workshop on work and fairness, the economic colloquium at the Technical University Darmstadt and the University of Dortmund for helpful discussions. All remaining errors are ours. 


\section{Introduction}

"If a picture (graph) is worth a thousand words, then a model is worth a thousand pictures (graphs)", F. Cunha, J.J. Heckman, L. Lochner, D. V. Masterov (2006, p.704).

Multiple skills are required for the formation of human capital. Besides of intelligence and language skills, motivation, self-regulation and social integration play an important role. The formation of cognitive skills depends on self-regulatory, noncognitive skills and vice versa and may vary between individuals and throughout the life span. Skill formation continues from birth until old-age and feedback effects between families, schools, peer groups and the labor market are important for individual development. The formation of skills is a cumulative, synergetic process which is affected by the environment, genetic endowments and both formal and informal investments in education.

Since "skills beget skills" (Cunha et al. (2006, p.702)) it follows that early investments will lead to higher returns than investments later on. Skills acquired in early childhood persist and help to build up future skills. The brain of newborns has a high degree of openness (see Knudsen et al. (2006)) and skill formation in early childhood seems to have lasting effects especially for the development of intelligence and self-regulation as well as for student achievement scores, socio-economic success and human capital (see Courchese et al. (2000), Cunha et al. (2006), Heckhausen and Heckhausen (2006), Rushton and Ankey (1996), among others).

Psychological research, for instance, is devoted to studying the interaction of newborns and parents in order to understand the experience of contingency. According to Heckhausen and Heckhausen (2006, p. 402) a dynamic, stable and responsive interaction fosters contingency experiences of the newborn which build the foundation of effort-regulation, persistence, patience and self-regulation throughout the life. Goal oriented action and persistence seem to be helpful for acquiring cognitive skills which foster learning in educational institutions and achievement scores later in life. If the experience of contingency is missing, the development of self-regulation and persistence can be distorted. Because of the cumulative and synergetic nature of skill formation this might have cumulative negative consequences for educational and labour market outcomes as well as for the formation of human capital.

In this study, we try to connect the economic literature on human capital formation with the biological and psychological literature on early childhood development and self-regulation. Our basic framework for assessing the distribution of age-specific returns to investment in skills is an elaboration of the model of skill formation from Cunha, Heckman et al. (2006) over the life cycle. Economics has a long tradition in studying the causes and consequences of human capital formation in educational 
institutions and labour markets (see Heckman et al. (2006), Rubinstein and Weiss (2006), among others). The relevance of skill formation in early childhood stems from a wealth of experimental and small scale longitudinal studies from biology, psychology and neuroscience (see Knudsen et al. (2006), Laucht (2005) and Heckhausen and Heckhausen (2006), among others).

However, empirical interdisciplinary research studying the cumulative and synergetic nature of investments in skills by families and schools is still hampered by incomplete data. Reasonable and representative life cycle data with information on the amount of investments and the quality of the environment as well as information on genetic endowments is largely missing (data in Germany is summarized in Konsortium Bildungsberichterstattung (2006)). Nevertheless, empirical assessments of the relative importance of pre-school, primary, secondary and post-secondary public and private investments in skills and human capital are crucial for policies in order to foster human capital and growth. Since the German economy will be more and more based on knowledge and science in the future, human capital is essential not only for individual well-being and social inclusion but also for competitiveness and openness of the economy.

Since data are incomplete, our contribution to the literature is simulation based evidence which is capable of illustrating the relationship between investment in skills, the technology of skill formation and the heterogeneous returns to age-specific investments in skills across the life span. Future social interdisciplinary research is necessary for understanding the types of interventions and investments which are helpful and optimal for fostering the different dimensions of skills and human capital.

The paper is related to the empirical literature on causal effects of schooling on wages and its inequality. Researchers are interested in the influence of education on various socio-economic outcome variables, among them human capital or wages, taking into account selectivity into various educational institutions. Preferences, ability, financial constraints and differences in the quality of schools may all influence the school choice of students which leads to heterogeneous individual returns to education. Furthermore, industrialized economies are characterised by continuing demographic and technological changes transmitted through labour markets as well as their regulation which in addition might influence the returns to education. As a consequence, there will be no homogenous or constant effect of an educational expansion but rather a distribution of individual effects (among others see Blundell et al. (2005), Card (2001), Flossmann and Pohlmeier (2006), Heckman et al. (2006) or Oreopoulos (2006)).

A significant part of the recent German literature on the returns to education has discussed data and methodological aspects of estimating returns to education (for re- 
cent surveys see Jochmann and Pohlmeier (2004), Flossmann and Pohlmeier (2006), and Pfeiffer (2000), among others). Estimates for homogenous or constant returns to education for Germany reveal values between 5 and 10 percent, depending on the instruments used, and the estimated average treatment effect of schooling varies between 4 and 9 percent. Whether the educational expansion form the seventies has contributed to rising rather than declining returns to education and the inequality of wages which started around 1998 is an issue of continuing research (Gernandt et al. 2006, Gebel and Pfeiffer 2007). In our current paper, we would like to address potential reasons for the heterogeneity in returns to education in Germany.

The model of the technology of skill formation is taking into account the changing nature of skill formation over the life span and the interdependency of cognitive and self-regulatory (non-cognitive) skills. More precisely, significant differences are modelled between skill formation both in early childhood and adolescence. On the one hand, the formation of a standard investment impulse in skills is the more productive the earlier in life it takes place. On the other hand, depreciation processes become quantitatively more important later on in life. In our model, the formation of skills in a certain period depends on the acquired skills from earlier periods and current investments. We simulate skill production functions with the characteristics of self-productivity and direct complementarities (Cunha et al. (2006)). The two concepts formalize some basic features of the nature of learning and skill formation:

1. Self-productivity (or recursive productivity): Skills of past periods remain productive for the attainment of current skills.

2. Direct skill complementarity: The higher the skill level the more productive may the return of subsequent investments in skills be.

Since skills are multiple by their nature, the technology of skill formation is multidimensional. In our model, the multidimensionality of skills is reduced to the two dimensions of cognitive and self-regulatory (non-cognitive) skills. The interactions among cognitive and self-regulatory skills and investments in these skills are modelled by a system of two interrelated production functions. The processes of depreciation of skills as well as aging are integrated into the simulation model. Additional heterogeneity of individuals stems from different family and social environments, different individual learning abilities and different degrees of complementarities between cognitive and self-regulatory skills in the production functions. In our model, human capital is a function of cognitive and self-regulatory skills as well as of mobility and aspects of the labour market such as regulation or the degree of wage flexibility.

The value of human capital of a standard simulated individual is adjusted such that it is equal to the value of an average German worker from the industry (which is approximately 900,000 million Euros). Furthermore, heterogeneity of cognitive and 
self-regulatory skills is adjusted in a way such that their interaction generates the distribution of the PISA 2000 achievement scores in reading for 16 year old German students. But the inequality of human capital is not only influenced by the heterogeneity of skills. Differences in individual mobility, labour markets and their institutions will transform skills into human capital and wages as well. Thus, the inequality of human capital will be adjusted to the ratio of the ninetieth to tenth percentile of the distribution of wages, for instance to the one in Germany or other countries. In Germany, this ratio was equal to 3 in 2004 compared to 2.5 in 1994 (see Gernandt and Pfeiffer (2006)). Thus, our simulation model illustrates the role of skill formation in early childhood for the growth of human capital (see also Dickens et al. (2006)) and changes in wage inequality, for instance.

With these adjustments we utilize the model

- to assess the distribution of returns to symmetric investment in both types of skills in different phases during child- and adulthood (pre-school, primary, secondary and post-secondary education),

- to assess the distribution of returns to investment in motivation and effortregulation during different phases of child- and adulthood,

- to highlight the role of complementarities between cognitive and selfregulatory skills for the returns to education,

- to compare the role of socio-economic family backgrounds and individual differences in learning capacities for the heterogeneity of returns to education,

- to highlight the role of life expectancy and age specific depreciation of skills for the heterogeneity of returns to education, and

- to contribute to the understanding of policies in order to foster human capital and growth and its distribution in the society.

The rest of the paper is organized as follows. In the next chapter we discuss some selected empirical evidence on skill acquisition over the whole life span which is helpful for justifying the structure and technology of skill formation. Chapter 3 elaborates the ingredients of the simulation model of skill formation in detail. In Chapter 4 we introduce the essential heterogeneity in skills and their formation over the life span and the calibration of the model parameters as well. The calibration will be based on stylized facts from the German educational and labour market system. Chapter 5 discusses various findings from the simulated relationship between the technology of skill acquisition and the heterogeneity of returns to education over the life cycle. Chapter 6 introduces into the discussion of equity and efficiency of agedependent investments into skill formation. Chapter 7 concludes. 


\section{Skill Formation over the Life Cycle}

\subsection{Cognitive Skills}

One central function in the technology of skill formation explains the relationship between cognitive skills and educational and environmental inputs as the relevant output over the life span. This function captures central findings from research on the development of the brain and of intelligence which we will briefly summarize in this part.

Cognitive skills include the ability to solve problems in general as well as language, memory capacity, and the speed of information processing. These skills are often measured by IQ tests. To observe the development across the life cycle, tests have been conducted for different age groups. Kaufmann et al. (1996) measure the differences on six core abilities for different age and educational groups ranging from ages 15 to 94 (see table 1). Since significant environmental and social changes took place during the last decades, Kaufmann et al. (1996) adjust the scores by using the education of the tested individuals. In industrialized countries, older generations typically score lower in ability tests compared to younger generations due to increasing education and improving environmental conditions during the $20^{\text {th }}$ century (Flynn (1987)).

One measure for cognitive skills is the ability of fluid problem solving. In one test individuals first have to arrange letters in order to form words and then discover secret letters in words. Fluid problem solving starts with an adjusted mean of 102.2 for the age of 15-16 and rises until the age of 20-24 where it peaks at 107.4 (Kaufmann et al. (1996)). Subsequently, it decreases with an accelerating speed reaching values below 100 at the age of 50 , and values of 82.6 for people older than 75 . The age groups of 60-65 and 65-69 have adjusted means which equal 87 percent of the adjusted mean for the 20-24 age groups.

Table 1: Cognitive abilities, brain and age

\begin{tabular}{|c|c|c|c|c|c|c|}
\hline & \multicolumn{6}{|c|}{ Approximate percentage of maximum value for different ages } \\
\hline Indicator & 0 years & 6 years & 16 years & 24 years & 65 years & 80 years \\
\hline Fluid Problem Solving Score & - & - & $95.2 \%$ & $100 \%$ & $87 \%$ & $77 \%$ \\
\hline Brain Mass & $27.4 \%$ & $81.4 \%$ & $96 \%$ & $100 \%$ & $94.5 \%$ & $91 \%$ \\
\hline Brain Volume & $23.6 \%$ & $92.9 \%$ & $100 \%$ & $100 \%$ & $82.9 \%$ & $75.7 \%$ \\
\hline
\end{tabular}

Source: Kaufmann et al. (1996), Courchese et al. (2000), own calculations.

Since differences in IQ tests at the age of ten have a high persistence over the life span, environment and investment during childhood are crucial for the formation of cognitive skills (see Armor (2003), Caspi (2005), Cunha et al. (2006), Weinert 
(2001)). These factors include in utero experiences, the way a mother interacts with her child, how the parents interact with each other as well as kindergarten and early years in school. The younger a child the larger are these influences on later cognitive development. Horwood and Fergusson (1998), for instance, study a birth cohort of 1,265 children in New Zealand and find that the duration of breastfeeding has a direct effect on the WISC-R total IQ score of 8 to 9 year old children. Furthermore, they find clear tendencies for a connection between an increasing duration of breastfeeding and decreasing levels of social and family disadvantage.

Thus, breastfeeding might indicate a positive, intensive relationship between the newborn and the mother and this, presumably, contributes to the formation of cognitive as well as other skills. While not breastfed children score with an average 97.78 IQ points at the age of 9 years, children that were breastfed score with an average of 102.8 IQ points. Likewise, children that were breastfed for a longer period of time score significantly higher in school achievement test scores. For a test score with a mean of 100 and a standard deviation of 10, not breastfed children score 97.78 in scholastic ability at the age of 13 and children breastfed for more than 8 month score with 103.05 points.

One indicator for brain size is the development of total brain volume. Starting with about $330 \mathrm{ml}$ at birth, the brain volume for males increases rapidly to 1,300 $\mathrm{ml}$ for 6 year old males, peaks with $1,400 \mathrm{ml}$ at the age of 16 and plateaus until the early 20s (Courchese et al. (2000)). Then it reduces to about 1,100 ml until the age of 75 to 80 being as small as the brain volume of a 2 year old. The brain volume decreases about 26 percent from the age of 16 until the age of $71-80$. This is even larger than the decrease of brain weight which is equal to about 9 percent for the same period (Courchese et al. (2000), see also Rushton and Ankey (1996) and for an earlier study Ho et al. (1980)).

Psychological research indicates that older compared to younger adults tend to have difficulties to realize multiple, complex intentions in their memory processes (for instance Kliegel et al. (2003)). Studies based on recently developed questionnaires like the Retrospective Memory Questionnaire (PRMQ) also suggest an age-related decline of memory performance (Kliegel and Jäger (2006), West (2005)). In addition to that, there might exist critical periods for the formation of cognitive skills. For instance, the language production centre (Broca's area) starts to develop after birth, peaks at the age of 7 months and continually declines afterwards (Oerter and Montanda (2002)). Early childhood in combination with the environment where it is formed is therefore the period in which the fundaments of cognitive skills are built (see also Amor (2003), Cunha et al. (2006)).

To sum up, measures of the brain and of cognitive ability reveal that a newborn has about 25-30 percent of the brain mass of a 25 year old adult. In early childhood, the 
brain grows quickly reaching about 81 percent of the maximum weight and 93 percent of the maximum volume at the age of 6 . After the age of 10 intelligence continues to grow, but further increases of cognitive skills after that age needs more investments. Starting at the age of 25 until the age of 80, the brain and memory processes for instance shrink once more and depreciation becomes important. The score for fluid problem solving reduces to about 77 percent of its maximum value, brain mass to about 91 percent and brain volume to about 74-79 percent. After the age of 80 the depreciation often seems to accelerate.

\subsection{Self-regulatory Skills}

The second function in the technology of skill formation explains the relationship between educational and environmental inputs and self-regulatory or non-cognitive skills over the life span. We try to model at least some crucial aspects of motivation and volition (effort-regulation and self-control) and its formation over the life cycle based on findings from motivation and developmental psychology which we will briefly summarize in this part.

Achievement tests measure the performance of children at school (e.g. in reading, mathematics). Here not only cognitive abilities, but self-regulatory (non-cognitive) skills are important. In order to properly use ones cognitive skills, a person has to be prepared for selecting her personal goals from the larger set of available goals (called motivation), has to be engaged in activities for achieving these goals (called volition) and has to evaluate whether the action was satisfactory (see Achtziger and Gollwitzer (2006)). These skills will be summarized in what is implied by the term self-regulation (or effort-regulation).

Goals as well as self-regulatory skills may continuously develop from childhood to adulthood (see Ericson (1963) and Heckhausen and Heckhausen (2006), among others). A significant part of self-regulation seems to be formed in early childhood, depending on the interaction between parents and the newborn. According to Heckhausen and Heckhausen (2006) the experience of contingency in these interactions (or its absence) is the fundament for motivation, self-regulation, volition and persistence (or its absence) throughout life. Cunha et al. (2006) find that achievement tests can be influenced until very high ages. This would suggest that self-regulatory skills can be improved more easily during adolescence than cognitive skills, for instance.

The importance of infancy on self-regulatory skills is still a field of considerable research. Based on the studies above our standard assumption will be that the dynamic of cognitive skill formation dominates in infancy. In a model variation presented in part 6 below it is further discussed how results change under the assumption that infancy is even more important for the development of self-regulatory skills than for cognitive development. 
Individuals seem to differ to a great deal with respect to these skills at all stages of the process of action. Psychological research has collected a wealth of findings on stereotypes and the role of unconscious actions. Limits to intentionality or goal oriented behaviour may be one consequence (see Ainslie (2001), Eliot and Dweck (2005), Heckhausen and Heckhausen (2006), among others). Individuals differ with respect to their ability or their willingness to delay gratification (time-preference, patience) and by how easily they are distracted (persistence). The impact of selfregulatory skills on socio-economic outcome variables can be immense. For example, Heckman et al. (2006) report that by increasing non-cognitive abilities to their highest level the probability for females to drop out of high school is reduced to virtually zero. According to Blanden et al. (2006) 20 percent of the relationship between parental income and children's later earnings is explained by the connection between parental background and the level of non-cognitive skills of the children.

Attempts to measure self-regulatory skills include the Thematic Apperception Test (TAT) (Spangler (1992)). It tries to tap a subject's unconscious to reveal repressed aspects of personality, motives and needs for achievement, power and intimacy, and problem-solving abilities. Schultheiss (2006) presents a system to elaborate TAT results that rates different individual types of motivation driven by the achievements motive, the power motive and the affiliation motive. Individuals invest effort in achieving different types of motives, thus TAT tests can be a useful indication of self-regulatory skills.

In psychology, five major personality traits are distinguished: extraversion, neuroticism, conscientiousness, agreeableness and openness to experience (Caspi et al. (2005)). Ashton and Lee (2001) find that, out of the Big Five personality traits, conscientiousness shows the highest correlation with various achievement scales. PRF (Jackson's Personality Research Form) achievement, for instance, contains items describing a competitive desire to succeed, a tendency to pursue difficult goals and a tendency to become deeply absorbed in hard work. Similarly, the JPI (Jackson Personality Inventory is widely considered to be one of the most psychometrically sound measures of personality) Energy Level scale contains items describing a preference for vigorous activity and for being busy as well as the tendency to perform intense work or recreational activity for long periods of time.

The correlation between the PRF achievement scale and conscientiousness is 0.56 and 0.3 with the JPI Energy level, respectively. Ashton and Pauonen (2001) report correlations between personality traits and school grades. Again, by having a significant correlation of 0.21 with school grades, conscientiousness seems to be the best predictor of all personality traits. Openness is also closely related, but is not well enough defined to be a reliable indicator for self-regulatory or other noncognitive skills determining achievement. This is due to the fact that openness con- 
tains some attributes that seem to be positively correlated with school grades and others that seem to be negatively correlated in the empirical analysis.

To sum up, even though self-regulatory skills are too diverse to be described by only one personality trait, there exists a significant relation to conscientiousness. Roberts et al. (2003) examine the development of personality in adulthood. They find that conscientiousness increases at a slowing rate starting at the age of 20 until middle age where it most likely plateaus. The evidence for self-regulatory development throughout old age seems to be more uncertain. However, important personality traits like conscientiousness seem to remain at a high level. Chasteen et al. (2001) suggest that self-regulatory competences like forming detailed implementation intentions can significantly improve the prospective memory in older individuals (mean age: 71 years). This would imply that higher levels of self-regulatory skills may compensate for lower level of cognitive skills in old age.

Traditional human capital theory predicts that incentives to invest in ones skills are the lower the nearer the age of retirement. Since, in addition to that, individuals in old age may suffer from more health problems this may lead to a decline in the motivation for pursuing other goals. Thus, this suggests that self-regulatory skills reach their maximum during mid to old age which is different to cognitive skills reaching their maximum during young adult age.

\subsection{The Cumulative and Synergetic Nature of Skill Formation}

Biological and environmental factors as well as their interactions affect the formation of cognitive and self-regulatory skills. "Skills beget skills" due to selfproductivity and direct complementarities (see Cunha et al. (2006)). The concept of self-productivity implies that skills attained in one developmental stage contribute to the attainment of further skills later on. To fix ideas, we introduce the formal structure of our model of skill acquisition which elaborates ideas taken from Cunha et al. (2006).

If we define $S_{t}$ as the level of skill $k$ in period $t$ the concept of self-productivity is captured by the assumption $\frac{\partial S_{t}^{k}}{\partial S_{t-1}^{k}}>0$. The concept of direct complementarities implies that investments in one period are the more productive in increasing the level of skills the more investment was conducted in earlier periods. The skill increase caused by an investment of a person with higher self-regulatory skills will be higher due to a higher level of self-regulation and persistence for using the investment. Further on, this will foster cognitive skills as well and may lay the foundation for success in academic achievement and in labour markets later in life. Let $I_{t}^{k}$ indicate investment in skill $k$ at age $t$. With a technology of skill formation $S_{t}^{k}=f_{t}^{k}\left(I_{t}^{k}, S_{t-1}\right)$ the 
concept of direct complementarity of skill $l$ on the output of skill $k$ is an assumption related to the second derivative: $\frac{\partial^{2} S_{t}^{k}}{\partial I_{t}^{k} \partial S_{t-1}^{l}}>0$.

Cunha et al. (2006) introduce a production function which takes into account the synergetic and cumulative nature of the formation of skills in the following way. In $t=1$ they assume an initial condition of $S_{1}^{k}=I_{1}^{k}$, where $k=C$ for cognitive skills and $k=N$ for self-regulatory (non-cognitive) skills. In the following period, $t=2$, skills are produced according to:

$$
S_{2}^{C}=\left\{\gamma_{1}\left(S_{1}^{C}\right)^{\alpha}+\gamma_{2}\left(S_{1}^{N}\right)^{\alpha}+\left(1-\gamma_{1}-\gamma_{2}\right)\left(I_{2}^{C}\right)^{\alpha}\right\}^{\frac{1}{\alpha}}
$$

and $S_{2}^{N}=\left\{\phi_{1}\left(S_{1}^{C}\right)^{\sigma}+\phi_{2}\left(S_{1}^{N}\right)^{\sigma}+\left(1-\phi_{1}-\phi_{2}\right)\left(I_{2}^{N}\right)^{\sigma}\right\}^{\frac{1}{\sigma}}$.

with $0 \leq \gamma_{i} \leq 1,0 \leq \phi_{i} \leq 1-\infty \leq \alpha \leq 1$ and $-\infty \leq \sigma \leq 1$.

The functions have the property of a constant elasticity of substitution where $\alpha$ and $\sigma$ govern the degree of complementarities between cognitive and self-regulatory skills in producing the new levels of skills as well as the degree of complementarities between investments and the amount of skills already available. If $\alpha=1$ or $\sigma=1$ the inputs of the production function are perfect substitutes, if $\alpha=-\infty$ or $\sigma=-\infty$ they are perfect complements which implies that all inputs are required in the same proportion since substitution is not possible. Varying the parameters $\alpha$ and $\sigma$ therefore allows to model critical as well as sensitive periods in the formation of different types of skills and their interaction.

\subsection{Human Capital}

Skill is the term that describes basic mental and physical abilities or competences a person acquires during her life span. In economics, the term human capital is used to describe the value these skills produce in the labour market or in self-employment. The human capital of an individual is thus the individual stream of earnings across the life span properly discounted and for example evaluated at the age of 18 . The returns to investments in skills will be assessed by the enhancement of human capital. Earnings and wages are determined by individual cognitive and self-regulatory skills and may further be determined by institutions like centralized or decentralized wage bargaining. The process of earnings starts after finishing school. Since technical change and a rising degree of specialisation are taking place in modern working places, the mobility between firms, occupations and regions is an integral part in the formation of human capital for establishing optimal matches between workers and jobs.

After schooling, individuals in our model will earn a wage corresponding to their human capital until the reach the age of retirement (65 to 70 years). Furthermore, in 
our simulation model the accumulation of human capital depends on cognitive and self-regulatory skills. In Germany, the average wage of a worker at the age of 40 is equal to 29,787 Euros in the industry (Statistical Yearbook Germany (2006)). The maximum of annual yearly earnings is assumed to be reached at the age of 55 which is comparable with empirical studies of earnings over the life cycle (see for example Franz (2006)). With these two "fix points" the accumulated nominal sum of human capital of a hypothetical worker working from the age of 18 to 65 will be 1.4 Million $€$ in our simulation model.

\section{A Model of Skill and Human Capital Formation}

In our simulation model of skill and human capital development over the life span, each period $t$ is supposed to be equivalent to one year of life. The theory behind equations (1) and (2) above provides a useful starting point for the development of the technology of skill formation across the life span, but for achieving our goal we need to impose more structure on the formation of cognitive and self-regulatory skills.

In principle, the relationship between in- and outputs may vary from year to year or between some well defined developmental phases. This would imply that all parameters of the production functions change. We chose an enhanced system of the two equations that specifies skill acquisition and depreciation on a yearly basis. The cumulative nature of learning is taken into account, together with the depreciation of skills. The plasticity of skills (Cunha et al. (2007)) and the relative amounts of adding new skills and losing available skills is changing with age. This implies for skill $k$ :

$S_{t}^{k}=$ learning $_{t-1}^{k}+S_{t-1}^{k}-$ losing $_{t-1}^{k}$

\subsection{Skill Formation}

On average, a young child learns easily even though it accumulated only a few skills during its short life. An older person, on the other side, managed to collect a high level of skills, but doesn't learn as fast as the young child with only a few skills. To model these differences we add two learning multipliers determining the persons' learning aptitude and depending on age to the basic function of skill formation, one for cognitive, $l_{t}^{\mathrm{C}}$, and one for non-cognitive skills, $\mathrm{l}_{\mathrm{t}}^{\mathrm{N}}$, respectively. For the moment we assume that $\gamma_{1}=\gamma_{2}=\phi_{1}=\phi_{2}=\frac{1}{3}, \alpha=\sigma$.

$$
\begin{aligned}
& \text { learning }_{t}^{C}=\psi^{C} l_{t}^{C}\left\{\frac{1}{3}\left(S_{t}^{C}\right)^{\alpha}+\frac{1}{3}\left(S_{t}^{N}\right)^{\alpha}+\frac{1}{3} \delta\left(I_{t}^{C}\right)^{\alpha}\right\}^{\frac{1}{\alpha}} \\
& \text { learning }_{t}^{N}=\psi^{N} l_{t}^{N}\left\{\frac{1}{3}\left(S_{t}^{C}\right)^{\alpha}+\frac{1}{3}\left(S_{t}^{N}\right)^{\alpha}+\frac{1}{3} \delta\left(I_{t}^{N}\right)^{\alpha}\right\}^{\frac{1}{\alpha}}
\end{aligned}
$$


$\alpha$ determines the degree of complementarities between cognitive and self-regulatory skills and $\psi^{C}$ and $\psi^{N}$ are some arbitrary adjustment factors for the units to measure skills. $\delta$ represents an individuals ability to transform investments into skills and is set equal to one for an average individual.

Early childhood is the most critical period for the development of skills. Within the first six years of life, the human brain has completed about $81-93 \%$ of its total growth (see part 2, table 1).

Growth processes of synapses and axons in the brain during early childhood inspired the numerical values of the cognitive multiplier. The visual and auditory cortex starts to develop shortly before birth having its fastest growth at the age of one month (Oerter and Montanda (2002)). From then on, the growing speed continuously declines. The development of the speech production centre (Broca's area) starts after birth as well, but peaks at the age of 7 months continually declining afterwards. The prefrontal cortex, being responsible for various regulation functions (e.g. planning complex cognitive behaviour, personality expression and moderating correct social behaviour), has its most rapid growth at the age of one to three years. It continues to grow during childhood until the age of 12 with a slowing speed. The numerical values for the cognitive learning multiplier, $\mathrm{l}_{\mathrm{t}}^{\mathrm{C}}$, from $t=0$ to $t=80$ are illustrated in Figure 1 for the period of 0 to 20 years. From 20 to 80 years they are assumed to slowly decrease to zero.

Figure 1: Cognitive learning multiplier from age 0 to 20

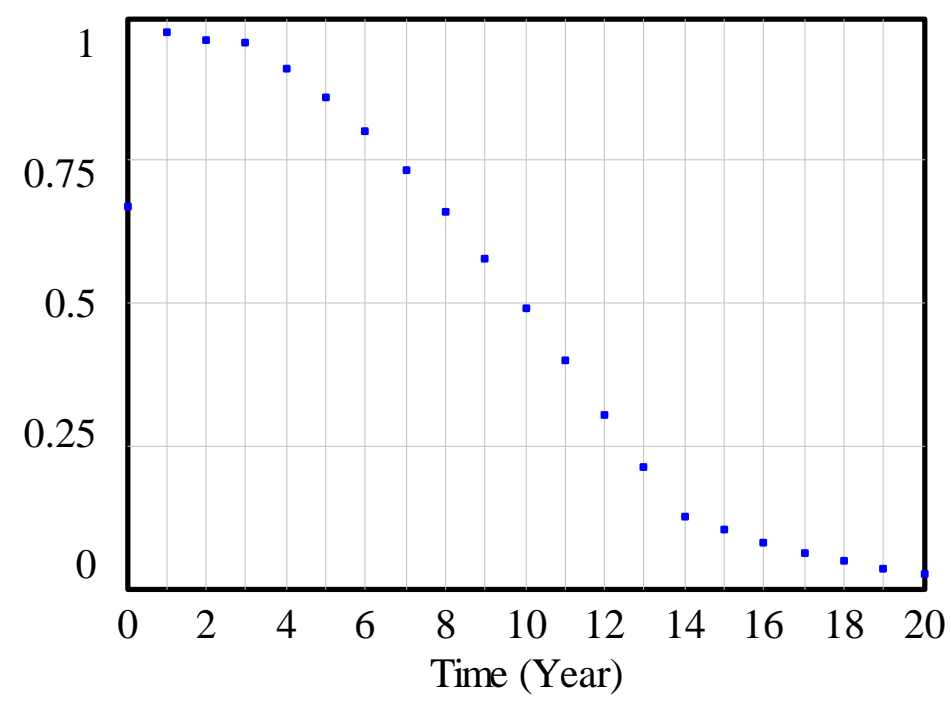

Self-regulatory skills seem to remain more malleable in adult age (see Cunha et al. (2006)), although this is subject to continuing research (see Heckhausen and Heckhausen (2006)). Personality traits closely related to some aspects of self-regulatory skills like conscientiousness or openness increase throughout young adult age until at least the age of 40 . Some of these empirical findings guided the way in which we 
model the numerical values of the non-cognitive learning multiplier, $\mathrm{l}_{\mathrm{t}}^{\mathrm{N}}$, as illustrated in Figure 2 from period 0 to 60 . In adolescence and adult age $l_{t}^{N}$ is significantly larger than $\mathrm{l}_{\mathrm{t}}^{\mathrm{C}}$.

Figure 2: Self-regulatory learning multiplier from age 0 to 60

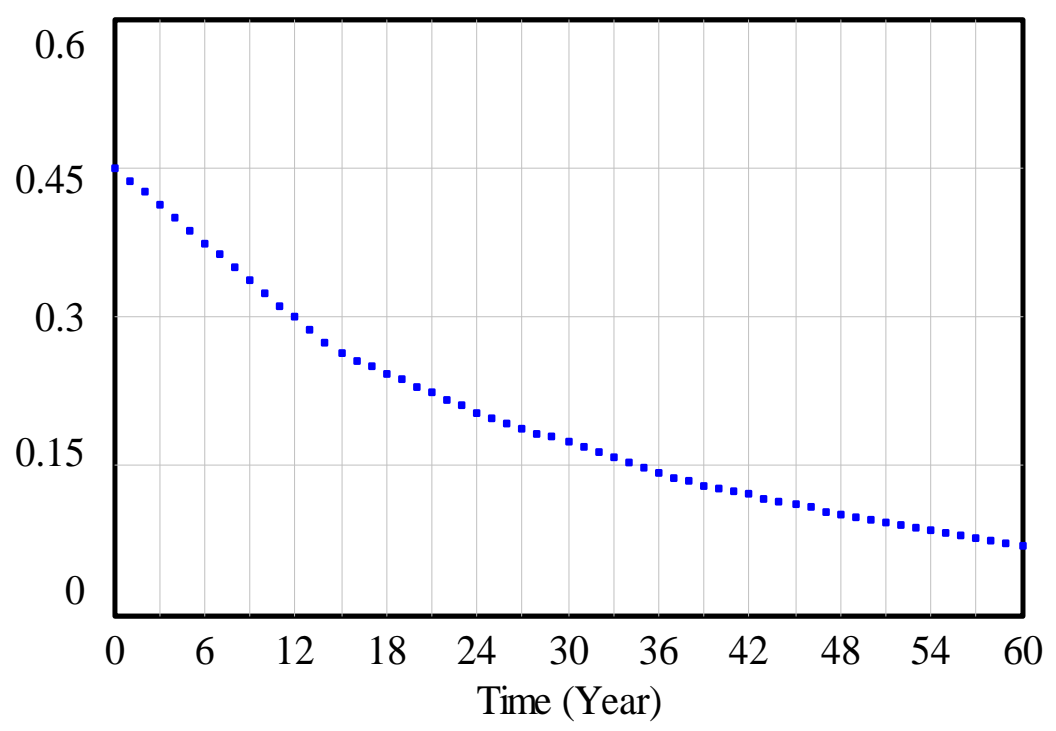

\subsection{Depreciation of Skills}

Research on the plasticity of the brain suggests that new neurons are formed continuously, however with a declining tendency across the life span (see Sugawa et al. (1996)). Since the depreciation of skills takes place all life, but with an increasing tendency, we may distinguish periods of growth from the decline of skill levels. Let $v_{t}$ be the number of periods needed until a person will loose all his skills completely given that no new investment takes place. Let $v_{t}^{C}=v_{t}^{N}=v_{t}$. Furthermore it is assumed that $\frac{\partial v_{t}}{\partial t}<0$ and $\frac{\partial^{2} v_{t}}{\partial^{2} t}=0$. The loss of skills increases with age, but the decrease in the loss of $v_{t}$ is assumed to be constant. Let as be the speed of aging within each period and let $L e$ be life expectancy. $L e$ is defined as the number of periods needed until $v_{t}=0$, defined as the moment when the individual loses all its skills immediately which can be interpreted as the death of this individual. For simplification we assume that $L e=80$ for all individuals in our simulation. This parameter will be changed for investigating its relevance for investments in skills. These assumptions lead to the following function for $v_{t}$ :

$v_{t}=a s \cdot(L e-t)$ 
For the starting period this implies: $v_{0}=a s$. Le. If $v_{t}$ is the amount of time it takes to depreciate the skill level to zero, annual depreciation will be:

losing $_{t}^{C}=\frac{S_{t}^{C}}{\text { as } \cdot(L e-t)}$

and

$\operatorname{losing}_{t}^{N}=\frac{S_{t}^{N}}{a s \cdot(L e-t)}$

\subsection{The Model of Skill Formation in Equations}

By substituting (4) and (7) into (3) one obtains equation 9 for cognitive skills:

$S_{t}^{C}=\psi^{C} \cdot l_{t-1}^{C} \cdot\left\{\frac{1}{3}\left(S_{t-1}^{C}\right)^{\alpha}+\frac{1}{3}\left(S_{t-1}^{N}\right)^{\alpha}+\frac{1}{3} \cdot \delta \cdot\left(I_{t-1}^{C}\right)^{\alpha}\right\}^{\frac{1}{\alpha}}+S_{t-1}^{C}-\frac{S_{t-1}^{C}}{a s \cdot[L e-(t-1)]}$

and equation 10 for self-regulatory (non-cognitive skills):

$$
S_{t}^{N}=\psi^{N} \cdot l_{t-1}^{N} \cdot\left\{\frac{1}{3}\left(S_{t-1}^{C}\right)^{\alpha}+\frac{1}{3}\left(S_{t-1}^{N}\right)^{\alpha}+\frac{1}{3} \cdot \delta \cdot\left(I_{t-1}^{N}\right)^{\alpha}\right\}^{\frac{1}{\alpha}}+S_{t-1}^{N}-\frac{S_{t-1}^{N}}{a s \cdot[L e-(t-1)]}
$$

Self-productivity $\left(\frac{\partial S_{2}^{k}}{\partial S_{1}^{k}}>0\right)$ for cognitive skills implies:

$$
\begin{aligned}
& \frac{\partial S_{t}^{C}}{\partial S_{t-1}^{C}}=1+3^{-(1 / \alpha)} \cdot \psi^{C} \cdot l_{t-1}^{C} \cdot S_{t-1}^{C(-1 / \alpha)} \cdot\left(\delta \cdot I_{t-1}^{C \alpha}+S_{t-1}^{C \alpha}+S_{t-1}^{N \alpha}\right)^{-1+(1 / \alpha)}-\frac{1}{a s+a s \cdot(L e-t)}>0 \\
& \Leftrightarrow 1+3^{-(1 / \alpha)} \cdot \psi^{C} \cdot l_{t-1}^{C} \cdot S_{t-1}^{C(-1 / \alpha)} \cdot\left(\delta \cdot I_{t-1}^{C \alpha}+S_{t-1}^{C \alpha}+S_{t-1}^{N \alpha}\right)^{-1+(1 / \alpha)}>\frac{1}{a s+a s \cdot(L e-t)} .
\end{aligned}
$$

Self-productivity for non-cognitive skills implies:

$$
\frac{\partial S_{t}^{N}}{\partial S_{t-1}^{N}}=1+3^{-(1 / \alpha)} \cdot \psi^{N} \cdot l_{t-1}^{N} \cdot S_{t-1}^{N}{ }^{(-1 / \alpha)} \cdot\left(\delta \cdot I_{t-1}^{N}+S_{t-1}^{C}+S_{t-1}^{N}\right)^{-1+(1 / \alpha)}-\frac{1}{a s+a s \cdot(L e-t)}>0 .
$$

For equation (11) the term $3^{-(1 / \alpha)} \cdot \psi^{C} \cdot l_{t-1}^{C} \cdot S_{t-1}^{C}(-1 / \alpha) \cdot\left(\delta \cdot I_{t-1}^{C}{ }^{\alpha}+S_{t-1}^{C}{ }^{\alpha}+S_{t-1}^{N}\right)^{-1+(1 / \alpha)}$ is always greater than zero. Thus, as long as $\frac{1}{a s+a s \cdot(L e-t)}$ is greater than 1 across the whole life span, skill formation can be characterised by self-productivity. This is satisfied for most values except for very small $a$ s and very large $t$. Even for $t=80$ selfproductivity will be satisfied as long as as $>1$. In the simulation model, as will have a value of 5.85 (see below). Condition (11) is therefore always satisfied and (12) analogously.

The degree of complementarities of skill $l$ for the production of skill $k$ is given by $\frac{\partial^{2} S_{t}^{k}}{\partial I_{t-1}^{k} \partial S_{t-1}^{l}}>0$. By using equations (9) and (10) it follows:

$\frac{\partial^{2} S_{t}^{C}}{\partial I_{t-1}^{C} \partial S_{t-1}^{N}}=\underbrace{\frac{1}{9} \cdot I_{t-1}^{C-1+\alpha} \cdot \psi^{C} \cdot l_{t-1}^{C} \cdot S_{t-1}^{N-1+\alpha} \cdot\left(\frac{I_{t-1}^{C \alpha} \cdot \delta}{3}+\frac{S_{t-1}^{C}}{3}+\frac{S_{t-1}^{N} \alpha}{3}\right)^{-2+(1 / \alpha)}}_{>0} \cdot \underbrace{\left(-1+\frac{1}{\alpha}\right) \cdot \alpha \cdot \delta}_{>0}>0$ 
It is easy to show that (13) is always true as long as $\alpha<1$, hence as long as there is no full substitutionality. The first part cannot be negative as long as the learning multiplier, investments and the level of skills are positive. For $1>\alpha>0$ the second part contains two positive factors being multiplied. For $\alpha<0$ two negative factors multiply to a positive product. Thus, the product cannot turn negative. Vice versa the same is true for $\frac{\partial^{2} S_{t}^{N}}{\partial I_{t-1}^{N} \partial S_{t-1}^{C}}$ since the only difference of equation (10) compared to (9) are the terms $\psi^{N}$ and $l_{t-1}^{N}$ which are always greater than zero just like $\psi^{C}$ and $l_{t-1}^{C}$.

\subsection{Achievement Scores and Human Capital}

The achievement an individual can reach in performing a task is a result of her cognitive and self-regulatory skills. The two skills are both necessary and they may, in fact in rather complex ways, interact for measured achievement tests. A person with a high level of cognitive skills may produce low results if she has only low motivation for participation. Thus, student achievement tests like PISA ("Programme for International Student Assessment") at the age of 16, IGLU ("Internationale Grundschule Lese-Untersuchung") at the age of 10 or DESI ("Deutsch Englisch Schülerleistungen International") measure the interaction of both cognitive and noncognitive skills. Several test procedures measure student performance in reading, mathematics or natural sciences (see for instance Weinert et al. (2006)). As a rule, the results of these different test scores have a correlation of approximately 70 percent (see for instance DIPF (2006)) which may result, for instance, from individually comparable levels of self-regulatory skills. In our model, the achievement score, $A_{t}$, is "produced" in each period by a Cobb Douglas function with equal weights of cognitive and non-cognitive skills:

$A_{t}=\psi_{A} \cdot \sqrt{S_{t}^{C} \cdot S_{t}^{N}}$

The factor $\psi_{A}$ is an adjustment factor for different levels of normalization of achievement scores and their distributions. The PISA test score will be given by $\mathrm{A}_{16}$ and IGLU by $A_{10}$. Human capital in a given year is modelled as a function of cognitive and self-regulatory skills and of the stock of human capital available from the previous year taking into account that human capital may depreciate, for example due to technological progress. Hence,

$$
H_{t}=\text { accumulation }_{t-q}^{H}+H_{t-1}-\text { depreciation }_{t-1}^{H}
$$

Various skills are necessary for the accumulation of human capital. A higher level of cognitive skills is as important as high levels of self-regulatory skills, of persistence and of self-regulation. The cumulative nature of human capital is modelled in a simple way. The third factor in the accumulation process is the available stock of human 
capital from the previous period. For reasons of simplicity we assume a Cobb Douglas production function for the accumulation process where each of the three factors has the same elasticity. The sum of the elasticities may vary with the parameter $\gamma$ and we will investigate the consequences for the distribution of the returns to education from varying gammas below. For high values of $\gamma$, large differences in skills will enhance differences in human capital. A small $\gamma$, on the other side, will lead to a smaller variation of human capital. For $\gamma=0$, human capital is the same for all skill levels.

Thus,

accumulation $_{t}^{H}=\psi_{H} \cdot\left(S_{t}^{\gamma^{\gamma \cdot \frac{1}{3}}} \cdot S_{t}^{N^{\gamma \cdot \frac{1}{3}}} \cdot H_{t}^{\gamma \cdot \frac{1}{3}}\right) \cdot$

The dimension of human capital is the EURO. This may be interpreted in a way that individuals get paid exactly according to the value of their human capital. Let $\psi_{\mathrm{H}}$ be the adjustment factor transforming skills and the stock of human capital into EUROs. Furthermore, a function is needed for the depreciation of human capital across the life span. Let $v_{t}^{H}$ be the number of periods needed until an individual will loose all its human capital completely given that no new investment in skills takes place. Since human capital depreciation accelerates as people become older it follows that:

$v_{t}^{H}=\vartheta^{H} \cdot v_{t}=\vartheta^{H} \cdot a s \cdot(L e-t)$

$\vartheta^{H}$ is the depreciation factor which may vary between individuals, jobs, industry and over time. For example, a higher $\vartheta^{H}$ will lead to an earlier human capital maximum in a job or an industry, a lower $\vartheta^{H}$ to a maximum later on. For some activities like soccer the maximum is reached early in life, but for others like philosophers the maximum may be reached later in life. Thus,

depreciation $_{t}^{H}=\frac{H_{t}}{v_{t}^{H}}$.

Inserting (17) in (18) and (18) together with (16) in (15), the full human capital equation is:

$H_{t}=\psi_{H} \cdot\left(S_{t-1}^{C} \gamma \cdot \frac{1}{3} \cdot S_{t-1}^{N} \gamma \cdot \frac{1}{3} \cdot H_{t-1}^{\gamma \cdot \frac{1}{3}}\right)+H_{t-1}-\frac{H_{t-1}}{\vartheta^{H} \cdot a s \cdot(L e-t+1)}$ 


\section{Creating Heterogeneity in Skill Formation}

\subsection{The "Standard" Individual}

The cognitive and self-regulatory skills of a standard individual are the result of equations (9) and (10) which interact for 80 periods. $\psi^{k}$ with $k=C, N$ is adjusted so that the level of cognitive skills at the age of 20 is $S_{20}^{C}=600$ for all types of complementarities. A standard individual is furthermore defined with $\alpha=0$. In this case, the CES function collapses to a Cobb Douglas production function for skills. Following results of Kaufman et al. (1996) (for more details see chapter 2 above) the adjusted mean of the fluid problem solving score of a 65 year old is equal to 87 percent of the adjusted mean for 20 year old individuals, which is equal to $S_{20}^{\mathrm{C}}$ (or 600).

as is adjusted in way such that the value for $S_{65}^{\mathrm{C}}$ in equation (9) is 87 percent of the value for $S_{20}^{\mathrm{C}}$. It turned out that this is the case for $a s=5.85$. For a newborn, the size of the brain is equal to about 25 to 30 percent of the brain value at young adult age. We assume $S_{0}^{C}$ to be 30 percent of $S_{20}^{C}$, hence we set $S_{0}^{C}=180$. Furthermore, each year the standard individual will invest one unit in both skills during its whole life which implies that $I_{t}^{k}=1$. For the standard individual the level of cognitive skills over the life cycle is illustrated in Figure 3.

Figure 3: Cognitive skills from age 0 to 80 (normalized between 0 and 600)

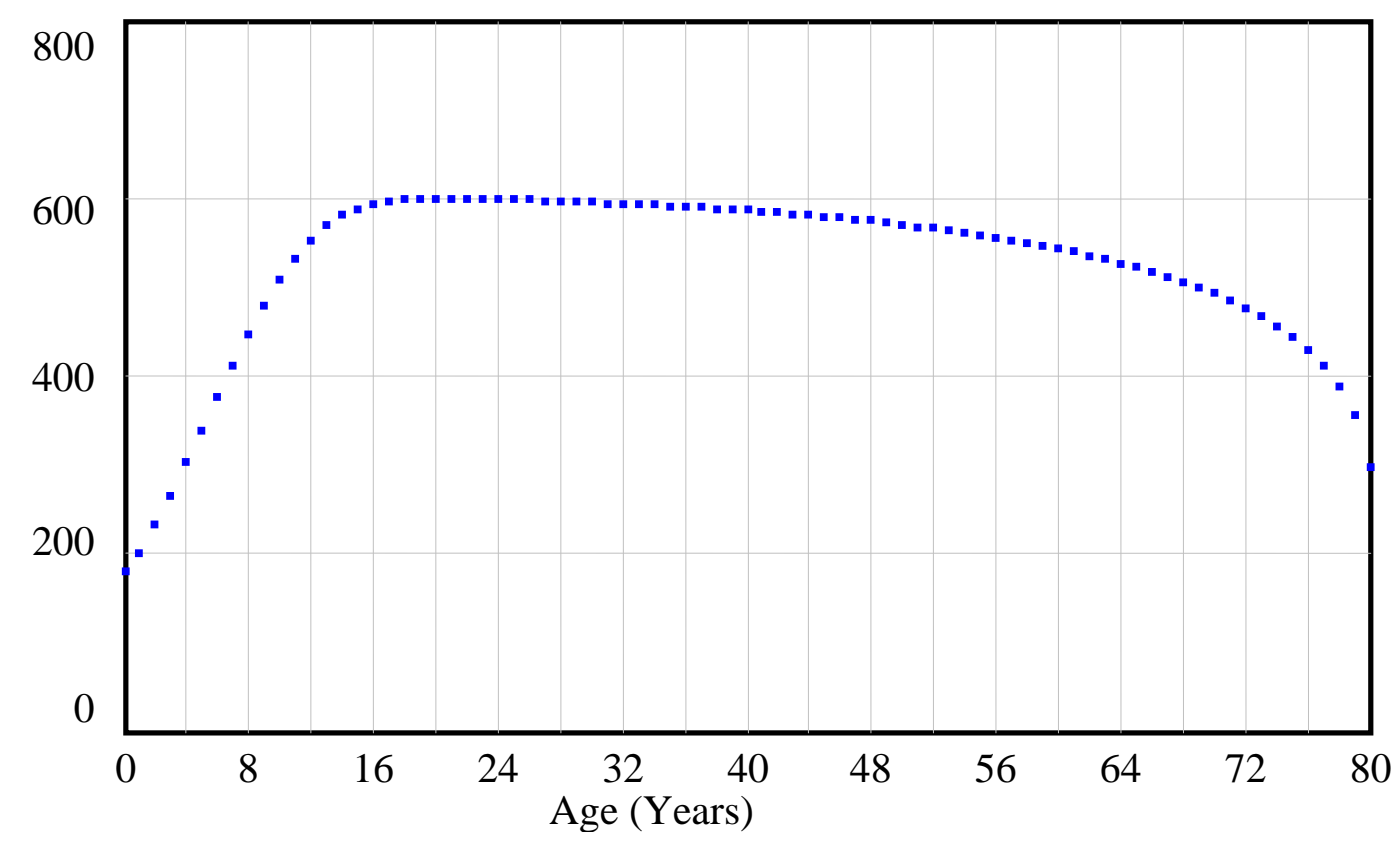

The figure replicates nicely psychological findings on the development of cognitive skills and intelligence across the life span ((Kaufmann et al. (1996), Courchese et al. (2000)). With those values, self-regulatory (non-cognitive) skills will peak at mid 
age matching the results in chapter 2.2. For the standard individual the level of selfregulatory skills over the life cycle is illustrated in Figure 4.

Figure 4: Self-regulatory (non-cognitive) skills from age 0 to 80 (normalized between 0 and 600)

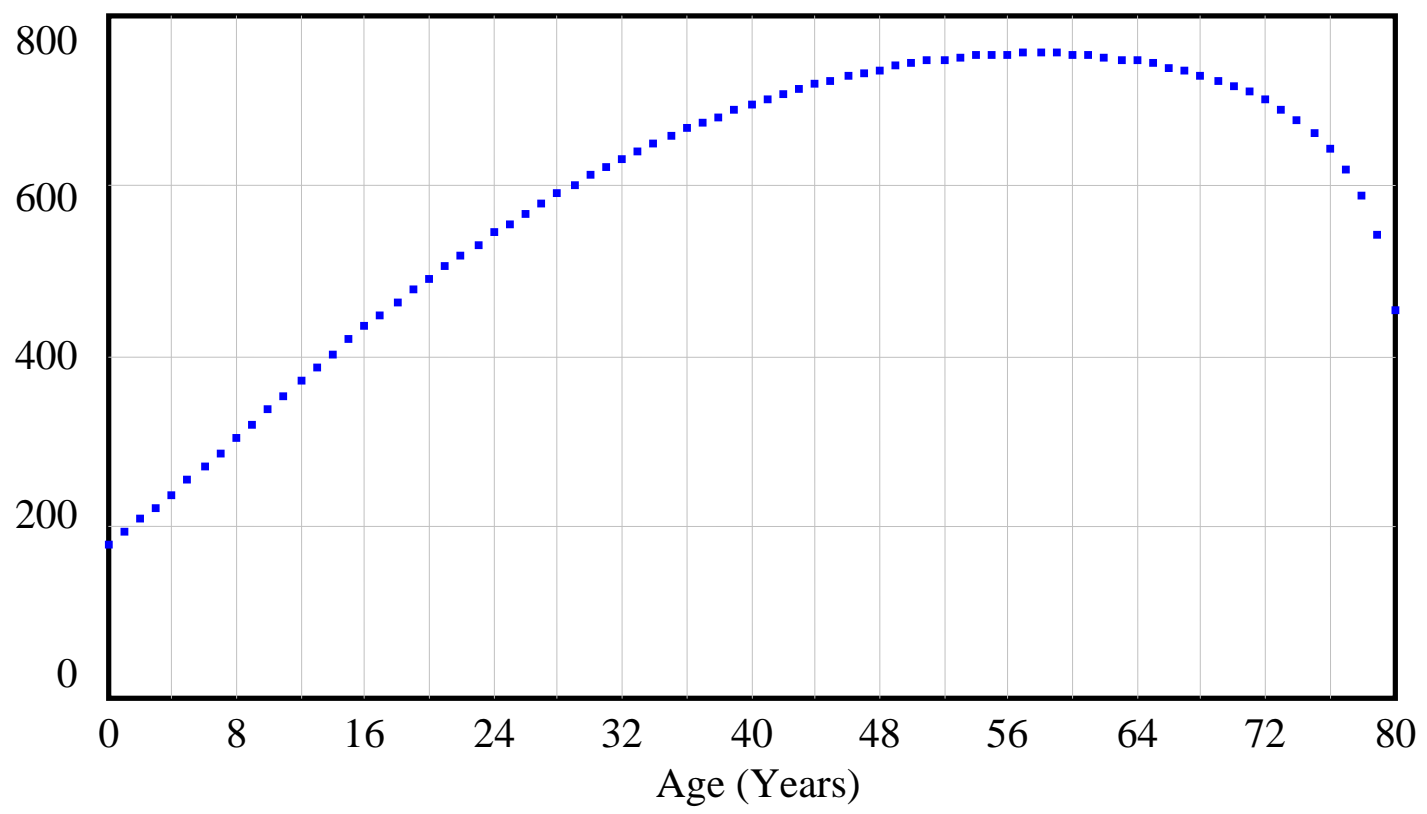

The figure replicates some findings on the development of self-regulatory skills and social integration across the life span (see chapter 2 above). After an adjustment of $\psi_{\mathrm{A}}$ in (14) such that $\mathrm{A}_{16}$ equals 507.77 (the PISA reading test value in Germany for the $50^{\text {th }}$ percentile (OECD (2000)), the achievement performance over the life cycle from equation (14) is illustrated in Figure 5. Achievement is influenced by both cognitive and self-regulatory skills and reaches its maximum around mid age. It captures the compensation of declining cognitive skills on the one hand and the effect that rising self-regulatory (non-cognitive) skills might have during mid adult age, the time when individuals are engaged in the labour market to create wages and additional human capital, on the other side.

The average annual wage of a worker in industries in Germany is 29,787 Euros (Statistical Yearbook Germany 2006). If we assume that an individual works from period 18 to period 65 her lifetime earnings will be around 1,400,000 Euros. $\psi_{H}$ in (19) is adjusted in a way so that this condition is satisfied. For standardization issues $\vartheta^{H}$ in (19) is always adjusted such that the human capital maximum is reached in $t=55$. Given theses adjustments the development of human capital across the life cycle for the standard individual is illustrated in figure 6 . For assessing the returns to investments in skills we will use the human capital accumulated over the life span. For this objective one needs to calculate the sum of properly discounted wages over some periods, here 18 to 65 , discounted to the age of 18 . Assuming a constant inter- 
est rate of 2 percent, the discounted lifetime income at period 18 of the standard individual is 821,274 €. Educational policies will be evaluated with respect to changes in the discounted lifetime income at the age of 18.

Figure 5: Achievement scores from age 0 to 80 (normalized to 500 at age 16)

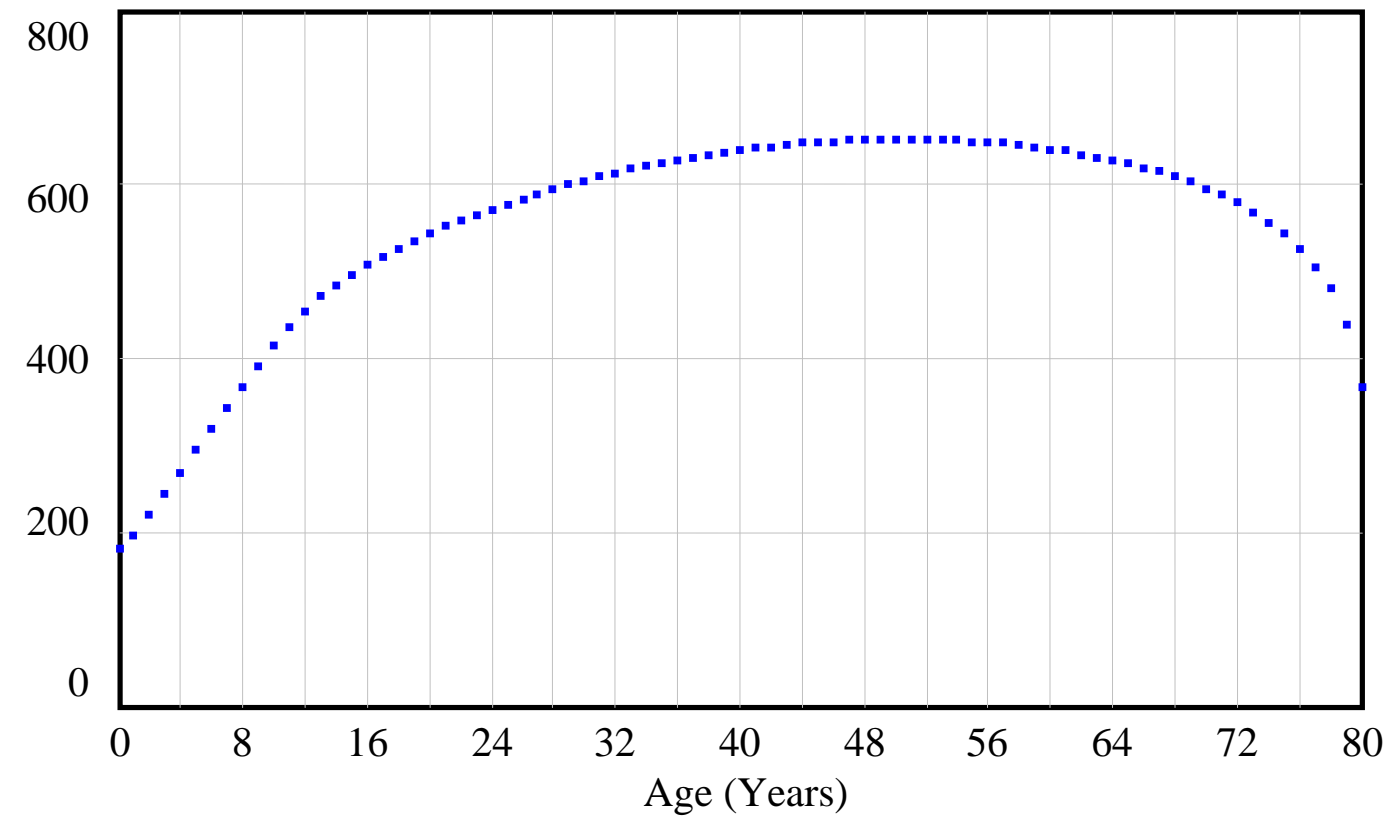

Figure 6: Annual human capital from age 0 to 80 (adjusted to 29,787 Euros at the age of 40)

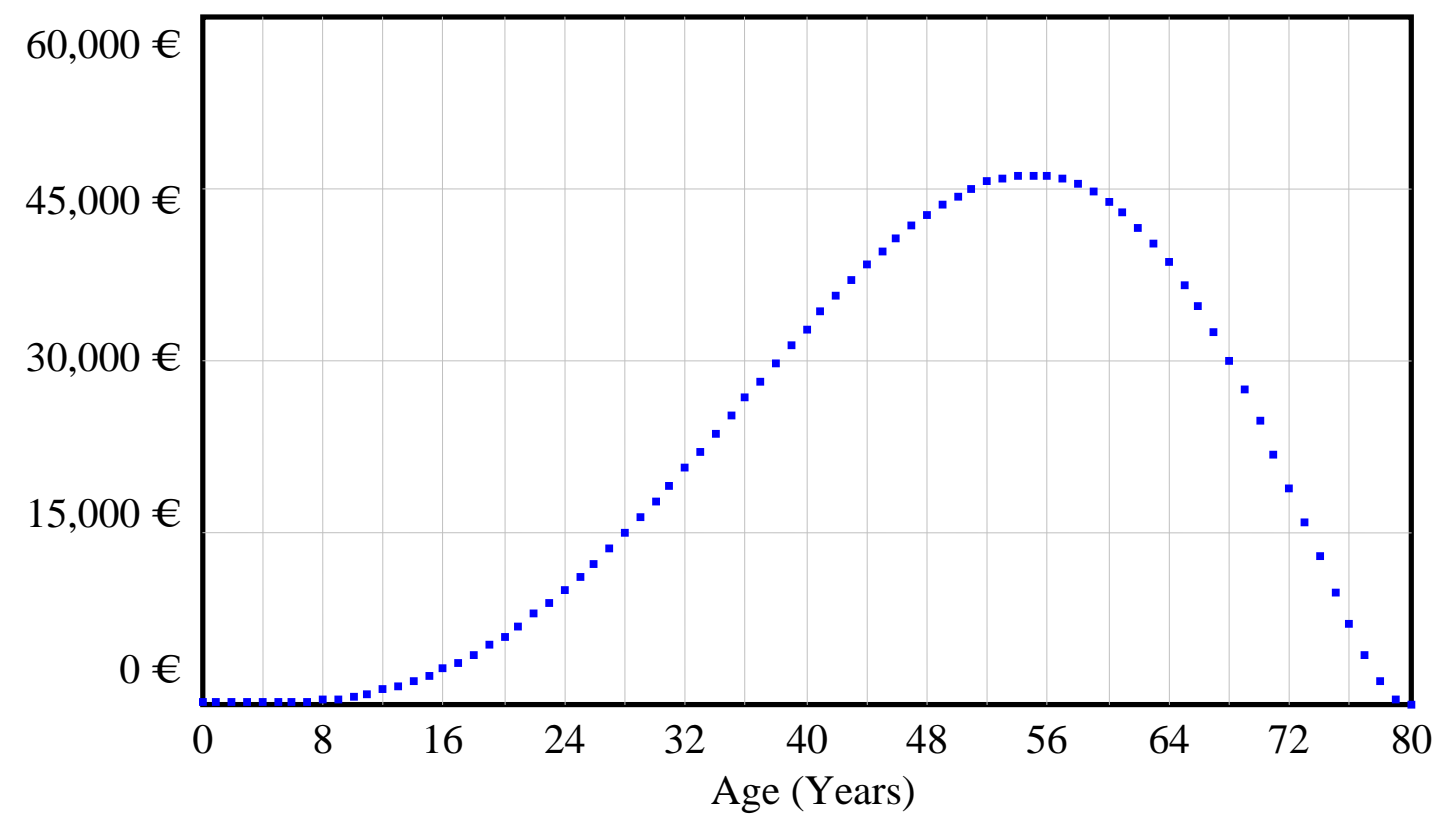

\subsection{Dimensions of Essential Heterogeneity in Skill Formation}

Four dimensions of essential heterogeneity in the technology of skills and the formation of skills and human capital over the life cycle and their consequences for the 
distribution of returns to education are modelled. They are rooted in the biological, psychological and socioeconomic nature of learning and skill formation.

The first dimension of essential heterogeneity is related to the age at which an investment in skills will be made. It results from the biological foundations of how human beings learn and develop skills and has already been discussed in detail above. A constant, for all individuals equal amount of investment in skills will produce age-specific decreasing returns to skills. For skill formation it therefore really matters at what age investments take place. From traditional human capital models, it is well-known that the shorter the time period until retirement the lower the incentive to invest in skills. The period which is left for harvesting is relevant. However, the dimension of heterogeneity which is introduced here is related to the age specific learning multipliers $l_{t}^{C}$ and $l_{t}^{N}$ originating from findings from neurobiology and psychology research on child development.

The second dimension of heterogeneity is a result of differences in individual learning capacities. In our interpretation this dimension of heterogeneity can best be related to individual differences in genetic endowments. Formally, individual giftedness is a variation of $\delta$ in equation (9) and (10). It is the way in which individuals transform a given, identical input into new skills. In this dimension we will once more assume that this type of heterogeneity remains constant across the life cycle. It will change the ability of skill acquisition and lead to different values for $\mathrm{A}_{16}$ equalling the PISA test scores in Table 2 and human capital with ceteris paribus identical amounts of investments.

In a variant, we model differences in the amount of cognitive and self-regulatory skills at the time when individuals are born. Prenatal conditions may matter for skill formation later on in life. A related literature investigates the determinants and consequences of birth weight. Black et al. (2005) for example find a significant impact of low birth weight on the IQ, education and earnings success of children. In the simulation model, differences in in utero conditions can be captured by $\mathrm{S}_{0}^{\mathrm{C}}$ and $\mathrm{S}_{0}^{\mathrm{N}}$. For simplicity reasons we model a symmetric variation of cognitive and selfregulatory skills. The two ways of modelling distinctions in genetic endowments differ, but in our model the consequences are rather similar.

The third dimension of essential heterogeneity is the degree of complementarities between cognitive and self-regulatory skills in the skill formation process, $\alpha$. $\alpha$ may be the result of individual differences in genetic endowments, as well as specific investments of parents or schools.

The fourth dimension of heterogeneity is the amount of investments in skills from the family or the social environment $\left(I_{t}^{C}, I_{t}^{N}\right)$. In the model, each family or social 
environment provides the individual with a different, symmetric and annually constant investment in cognitive and self-regulatory skills from period 0 to 80 . Individuals living in an unfavourable environment constantly receive low investments corresponding to lower educational and labour market outcomes. Individuals living in favourable environments, on the other side, profit from higher skill investments throughout their lives leading to higher educational and labour market outcomes. In one variant of the model, the investment impulse will last only until the age of 18; for the rest of the life span, the impulse is again constant for all individuals. In a second variant of the model, we compare the consequences for the distribution of the returns to education for investments in self-regulatory skills $\left(I_{t}^{N}\right)$.

The fourth dimension of essential heterogeneity is related to the amount of educational investments an individual receives. Families may differ with respect to their size and stability, the amount of cognitive and self-regulatory skills of the parents and other family members, and their human capital. Influences from the environment stem from the neighbourhood, the quality of schools or the infrastructure in the region where the children grow up. There exists a rich economic and sociological literature contributing to the relevance of these environmental factors for the individual development of skills. In our model, altering the amount of investments in the skills of children is the way a society may try to influence the distribution of skills and human capital and compensate for environmental disadvantages.

Recently, the distributions of achievement scores for 16 year old students in reading, mathematics and natural sciences have received a great deal of attention. Achievement scores can best be understood as a function of cognitive and self-regulatory skills. For the purpose of calibrating our simulation model we use the PISA 2000 (OECD (2000)) reading test scores for German students from different types of schools, see Table 2 .

Table 2: Percentiles of PISA reading test scores for Germany

\begin{tabular}{c|c} 
& PISA reading score/ $\mathrm{A}_{16}$ \\
\hline $1 \%$ & 236.57 \\
$10 \%$ & 362.7 \\
$25 \%$ & 438.95 \\
$50 \%$ & 507.77 \\
$75 \%$ & 568.64 \\
$90 \%$ & 619.8 \\
$99 \%$ & 707.23
\end{tabular}

Source: PISA 2000, OECD, own calculations. 
In different simulation models, the parameters of essential heterogeneity in the two basic skill production functions are chosen such that they generate the PISA distribution according to equation 14 at the age of sixteen. After dropping the duplicates 4,432 unique observations remained. From these observations we derive seven percentiles for the scores of reading performance (see Table 2). That way a heterogeneous population in achievement scores at the age of sixteen consisting of seven individuals is modelled.

Table 3 summarizes the parameter variations causing the PISA distribution on the basis of equation 14 .

Table 3: The PISA distribution for different types of heterogeneity

\begin{tabular}{|c|c|c|c|}
\hline Percentile & $\begin{array}{c}\text { Variation of } \\
\mathrm{I}_{0}^{\mathrm{k}} \ldots \mathrm{I}_{80}^{\mathrm{k}}\end{array}$ & Variation of $\delta$ & $\begin{array}{c}\text { Variation of } \\
\mathrm{S}_{0}^{\mathrm{C}} ; \mathrm{S}_{0}^{\mathrm{N}}\end{array}$ \\
\hline $1 \%$ & 0.01467 & 0.24478 & 57.613 \\
\hline $10 \%$ & 0.2611 & 0.63915 & 110.747 \\
\hline $25 \%$ & 0.5884 & 0.838 & 146.27 \\
\hline $50 \%$ & 1 & 1 & 180 \\
\hline $75 \%$ & 1.452 & 1.13238 & 210.945 \\
\hline $90 \%$ & 1.8929 & 1.23701 & 237.66 \\
\hline $99 \%$ & 2.7684 & 1.40414 & 284.62 \\
\hline
\end{tabular}

For instance, a student at the $99^{\text {th }}$ percentile in the PISA test receives ceteris paribus skill investments that are 2.7684 times higher than those of the $50^{\text {th }}$ percentile, defined as the "standard individual" (column 2). The individual learning ability of a student at the $99^{\text {th }}$ percentile will be, ceteris paribus, 1.40414 times as high as the one of the standard individual (column 3). The starting values of skills at the time of birth of a student at the $99^{\text {th }}$ percentile will be, ceteris paribus, 284.62, compared to 180 of the standard individual (column 4).

The simulation of human capital over the life cycle is based on equation (19). Figure 7 illustrates the level of cognitive and self-regulatory skills, achievement and human capital for a population of heterogeneous skill investments during childhood on an annual basis. 
Figure 7: A population of seven individuals with heterogeneous environments
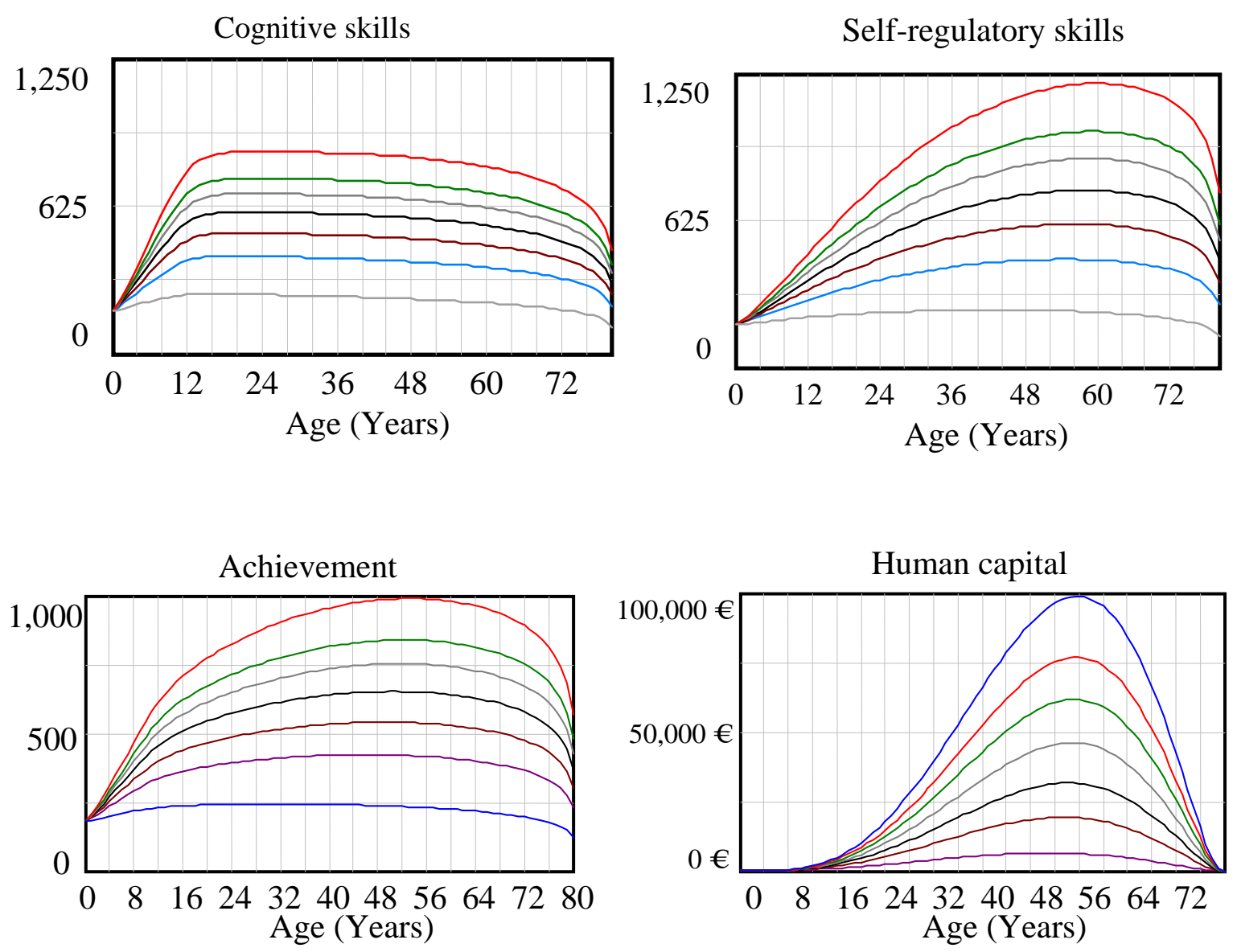

Next, we turn our attention to the synergetic nature of skill formation, modelled by variations of the degrees of complementarities. Our approach is an empirical one. To test the validity of several complementarities we run simulations for different values of $\alpha$. In all variants of the model an adjustment of $\psi^{k}$ for $k=C, N$ guarantees that $S_{20}^{k}=600$ for all complementarities. This adjustment is necessary since different values for $\alpha$ cause large numerical differences in the CES production function learning $t_{t}^{k}$, but leave losing $_{t}^{k}$ basically unchanged.

Table 4 contains the implied variations of $I_{t}^{k}$ for different values of $\alpha$ in (9) and (10) such that the achievement scores modelled in equation (14) replicate the PISA achievement reading scores. Table 5 contains the implied variations of $S_{0}^{\mathrm{C}}$ and $S_{0}^{\mathrm{N}}$, the skills at birth, for different values of $\alpha$ such that the achievement scores replicate the PISA reading scores. Recall that $\alpha=1$ leads to complete skill substitutionality, $\alpha=0$ to the Cobb Douglas case with an elasticity of substitution of 1 and $\alpha=-\infty$ to full complementarity. 
Table 4: Parameter variations causing the PISA distribution for different environments

\begin{tabular}{|c|c|c|c|c|c|}
\hline \multicolumn{7}{|c|}{ Variation of I $\mathrm{I}_{\mathrm{t}}^{\mathrm{k}}$} \\
\hline Percentile & $\alpha=-100$ & $\alpha=-0.3$ & $\alpha=0$ & $\alpha=0.3$ & $\alpha=1$ \\
\hline $1 \%$ & 0.2 & 0.14 & 0.01467 & - & - \\
\hline $10 \%$ & 0.56 & 0.512 & 0.2611 & - & - \\
\hline $25 \%$ & 0.79 & 0.763 & 0.5884 & 0.004 & - \\
\hline $50 \%$ & 1 & 1 & 1 & 1 & 1 \\
\hline $75 \%$ & 1.183 & 1.215 & 1.452 & 4.8 & 392 \\
\hline $90 \%$ & 1.338 & 1.4 & 1.8929 & 11 & 724 \\
\hline $99 \%$ & 1.605 & 1.725 & 2.7684 & 28.3 & 1,300 \\
\hline
\end{tabular}

Table 5: Parameter variations causing the PISA distribution for different starting conditions

\begin{tabular}{|c|c|c|c|c|c|}
\hline \multicolumn{7}{|c|}{ Symmetric variation of $S_{0}^{\mathrm{C}}$ and $\mathrm{S}_{0}^{\mathrm{N}}$} \\
\hline Percentile & $\alpha=-100$ & $\alpha=-0.3$ & $\alpha=0$ & $\alpha=0.3$ & $\alpha=1$ \\
\hline $1 \%$ & - & 7.3 & 57.613 & 79.6 & 83.7 \\
\hline $10 \%$ & 33 & 71 & 110.747 & 125.9 & 128.5 \\
\hline $25 \%$ & 110 & 125.7 & 146.27 & 154.25 & 155.3 \\
\hline $50 \%$ & 180 & 180 & 180 & 180 & 180 \\
\hline $75 \%$ & 242 & 230 & 210.945 & 203 & 201.5 \\
\hline $90 \%$ & 294 & 274 & 237.66 & 222 & 219.5 \\
\hline $99 \%$ & 384 & 351 & 284.62 & 255.4 & 251 \\
\hline
\end{tabular}

In the case of high complementarity with $\alpha=-100$, starting values vary between 384 and 0 to bring out the PISA distribution at the age of 16 (Table 5). The variation of the starting conditions becomes smaller with a lower $\alpha$. With $\alpha=1$, starting values vary between 251 and 83.7 to generate the PISA distribution. Heterogeneity is even more sensitive to variations of the environment for different values of complementarities (see Table 4). With $\alpha=1$, for instance, the 99 percent student must receive an amount of investment 1,300 times as large as the one for 5099 percent students. By assuming high skill complementarities, inequality at birth can thus more easily be compensated by later skill investment. In the case of a high degree of complementarities, skill investments throughout the life span play a more crucial role compared to in utero conditions. 
For the case of $\alpha=0$, both starting conditions and skill investments in childhood have a significant effect. Students at the $1^{\text {st }}$ percentile of the PISA distribution with average starting conditions will receive almost no skill investment while students of the $99^{\text {th }}$ percentile with average starting conditions receive a skill investment which is 2.7684 times larger than investments for the $50^{\text {th }}$ percentile. Finally, considering full substitutionality with $\alpha=1$ there is no bottleneck in the production of skills, thus favourable starting conditions alone will bring the individual almost to an average skill level even if no further investments are undertaken. Starting conditions determine the skill development throughout life and investments during childhood barely have any influence.

From our point of view, the results indicate that the Cobb Douglas case $(\alpha=0)$ is a reasonable model of the synergetic nature of learning with multiple inputs in the case of Germany. It seems to already capture some aspects of the trade off in the technology of skill formation between skill investments throughout childhood and starting conditions. With the extreme values of $\alpha$, the results are less convincing. Therefore, in the following we will proceed with the assumption $\alpha=0$.

\subsection{Mobility and the Heterogeneity of Labour Markets}

The inequality of skills will be transformed in wage and earnings inequality as well. In addition to that, mobility between jobs, occupations, firms and regions is crucial for the matching of supply and demand and for wage determination. Furthermore, these processes are influenced by differences in labour regulation, wage determination and the social transfer system. For instance, the inequality of wages may be restricted by minimum wages or social transfers for those who are not employed or by collective wage bargaining. To adjust our simulation results to the German labour market we use the 90-10 ratio of inequality in earnings which is approximately equal to 3 (Gernandt und Pfeiffer (2006), OECD (2006a)). By an adjustment of $\gamma$ and $\psi_{H}$ in (19) the model can be calibrated to any empirical wage distributions. After the adjustment, the accumulated income of the $90^{\text {th }}$ percentile in period 65 is 3 times larger than the accumulated income of the $10^{\text {th }}$ percentile. Thus, inequality in human capital is a result of the inequality of skills and of differences in labour markets.

It turns out that inequality arising through the labour market equals the measured wage inequality in Germany for $\gamma=1.58$. When $\gamma=0$ there is no wage inequality at all even in the case when educational levels differ substantially. Figure 8 illustrates these adjustments. It is obvious that labour market characteristics determine the returns to education in our simulation model. In our model, the returns to education are the higher the greater the inequality of wages will be. This result seems to be in line with recent findings on rising returns to education in Germany and other industrialized countries (see for instance Gebel and Pfeiffer (2007)). If there was no wage or income inequality nobody would gain from more education. 
Figure 8: Simulations of labour market inequality

Human capital

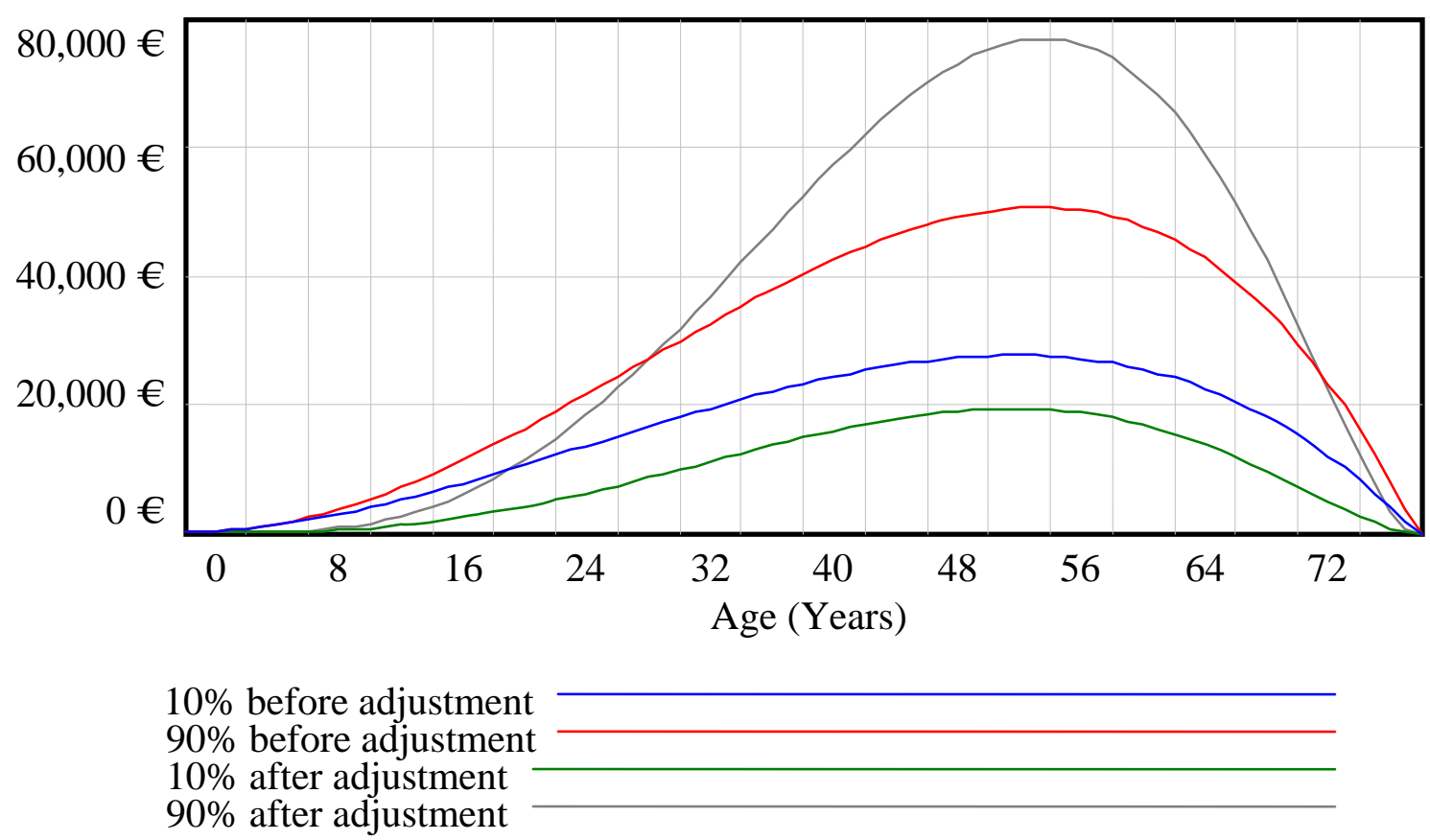

\section{Simulation Results}

\subsection{Returns to Symmetric Investments in Skills}

This chapter discusses the simulation results for the returns to education at different ages during childhood and young adult age. It is assumed that the seven individuals of our heterogeneous population work from the age of 18 until the age of 65 while accumulating earnings. The amount of human capital of each individual is defined as the present value of the sum of annual earnings evaluated at age of 18 . The interest rate is assumed to be 2 percent. Individual returns to education will be measured by the percentage change of the present value of the accumulated lifetime income in period 18 due to additional age-dependent educational impulses.

Two sources of essential heterogeneity introduced in part 4.2 are investigated: inequality of skills as a consequence of inequality from the environment and of inequalities in individual giftedness in learning. Given these two dimensions of heterogeneity together with the age-dependent variations of the learning multipliers, we assess the distribution of the returns to education for different educational policies. In this part, we model four different types of educational investments. The first one is called the preschool impulse which provides an additional constant skill investment lasting six years from the age of 0 until 5 . The second one is a primary school impulse which lasts from period 6 to 11 . The third one is a secondary school impulse from period 12 to 17 and the fourth one is a tertiary educational impulse lasting form 
18 to 21 . The tertiary educational impulse is specific in the sense that individuals have to sacrifice four years of income in order to attend this education. If a person chooses to attend a tertiary education she will only receive earnings from period 22 to 65 .

Furthermore, individuals will receive an additional, symmetric skill investment of $\mathrm{I}_{\mathrm{t}}^{\mathrm{k}}=5, \mathrm{k}=\mathrm{c}, \mathrm{n}$ in both cognitive and regulatory (non-cognitive) skills. The EURO cost of an annual investment impulse is given by 5,627 $€$ which is equal to the estimated average of educational investments per student in Germany in the year 2005 (OECD (2006b)). In our model, we assume that an individual has to pay 5,627 € per annum for this additional educational impulse. Table 6 shows the total gains in human capital measured in EUROS for each of the seven individuals whose heterogeneity stems from different environments (variations of $\mathrm{I}_{0}^{\mathrm{k}} \ldots \mathrm{I}_{80}^{\mathrm{k}}$ ). Table 7 shows the corresponding distributions of individual returns to education.

Table 6: Returns to education in monetary units for the percentiles in heterogeneous societies (discounted to period 18)

\begin{tabular}{|c|c|c|c|c|}
\hline Percentile & $\begin{array}{c}\text { Impulse } \\
\mathrm{I}_{0}^{\mathrm{k}} \text { to } \mathrm{I}_{5}^{\mathrm{k}}\end{array}$ & $\begin{array}{c}\text { Impulse } \\
\mathrm{I}_{6}^{\mathrm{k}} \text { to } \mathrm{I}_{11}^{\mathrm{k}}\end{array}$ & $\begin{array}{c}\text { Impulse } \\
\mathrm{I}_{12}^{\mathrm{k}} \text { to } \mathrm{I}_{17}^{\mathrm{k}}\end{array}$ & $\begin{array}{c}\text { Impulse } \\
\mathrm{I}_{18}^{\mathrm{k}} \text { to } \mathrm{I}_{21}^{\mathrm{k}}\end{array}$ \\
\hline $1 \%$ & $449652 €$ & $224646 €$ & $38540 €$ & $-4336 €$ \\
\hline $10 \%$ & $618398 €$ & $355002 €$ & $91729 €$ & $8966 €$ \\
\hline $25 \%$ & $704126 €$ & $424170 €$ & $121686 €$ & $15668 €$ \\
\hline $50 \%$ & $773887 €$ & $481201 €$ & $146909 €$ & $20597 €$ \\
\hline $75 \%$ & $831012 €$ & $528106 €$ & $167854 €$ & $24065 €$ \\
\hline $90 \%$ & $876492 €$ & $565456 €$ & $184584 €$ & $26345 €$ \\
\hline $99 \%$ & $950252 €$ & $625836 €$ & $211614 €$ & $29005 €$ \\
\hline
\end{tabular}

The numbers indicate that the earlier in childhood a skill investment is provided the higher the return for the individual, both measured in absolute values as well as in returns to education. One reason for early investments in skills having a greater benefit over the life cycle is due to the fact that the learning multiplier $l_{t}^{k}$ is higher in young age. More important, however, is the cumulative nature of skill formation due to self-productivity and direct complementarities. These basic learning characteristics make childhood and very early childhood crucial for the formation of human capital. 
Table 7: Individual returns to education for the percentiles in heterogeneous societies

\begin{tabular}{|c|c|c|c|c|}
\hline Percentile & $\begin{array}{c}\text { Impulse } \\
\mathrm{I}_{0}^{\mathrm{k}} \text { to } \mathrm{I}_{5}^{\mathrm{k}}\end{array}$ & $\begin{array}{c}\text { Impulse } \\
\mathrm{I}_{6}^{\mathrm{k}} \text { to } \mathrm{I}_{11}^{\mathrm{k}}\end{array}$ & $\begin{array}{c}\text { Impulse } \\
\mathrm{I}_{12}^{\mathrm{k}} \text { to } \mathrm{I}_{17}^{\mathrm{k}}\end{array}$ & $\begin{array}{c}\text { Impulse } \\
\mathrm{I}_{18}^{\mathrm{k}} \text { to } \mathrm{I}_{21}^{\mathrm{k}}\end{array}$ \\
\hline $1 \%$ & $27.74 \%$ & $17.79 \%$ & $4.29 \%$ & $-0.82 \%$ \\
\hline $10 \%$ & $17.87 \%$ & $11.92 \%$ & $3.78 \%$ & $0.60 \%$ \\
\hline $25 \%$ & $14.17 \%$ & $9.59 \%$ & $3.23 \%$ & $0.67 \%$ \\
\hline $50 \%$ & $11.70 \%$ & $7.99 \%$ & $2.78 \%$ & $0.62 \%$ \\
\hline $75 \%$ & $10.00 \%$ & $6.88 \%$ & $2.44 \%$ & $0.55 \%$ \\
\hline $90 \%$ & $8.83 \%$ & $6.10 \%$ & $2.20 \%$ & $0.49 \%$ \\
\hline $99 \%$ & $7.26 \%$ & $5.06 \%$ & $1.85 \%$ & $0.40 \%$ \\
\hline
\end{tabular}

Individuals from more disadvantaged environments receive lower absolute increments of human capital even though their (relative) returns are always higher. Those starting with a relatively low skill level will profit less from an additional investment impulse in terms of additional absolute monetary earnings (cp. table 6). So it follows that if society is interested in maximizing the total amount of human capital, additional scarce resources should ideally be invested in children from bright environments. However, the relative gains (the additional earnings in percent of actual earnings) are significantly higher for individuals from disadvantaged environments (cp. table 7). This has two reasons. First, individuals from disadvantaged environments start with lower levels of investments and skills. Therefore, self-productivity and direct complementarities start with lower inputs leading to lower long run returns. And second, the marginal rate of return to additional investments is decreasing in the CES production function. Individuals with a higher skill level will benefit relatively less from an additional skill investment. Both effects together surpass the positive effect of skill complementary on individual rates of return. Thus, if society is interested in maximizing the relative gains in earnings and human capital, it follows that additional scarce resources should ideally be invested in children from disadvantaged environments.

With age increasing, the costs of education become higher than the benefits. Thus, for a tertiary educational investment not the $1^{\text {st }}$, but the $25^{\text {th }}$ percentile receives the highest individual returns. This is due to the fact that the $1^{\text {st }}$ percentile has a benefit smaller than the costs and thus has a negative return to tertiary education. The $25^{\text {th }}$ percentile, on the other side, has the highest individual educational return in this scenario because not only is the benefit significantly higher than the cost of education, but also is the level of skills still small enough to generate a high individual rate of return. 
Table 8 illustrates the individual returns to education for the second scenario where heterogeneity is caused by a variation of $\mathrm{I}_{0}^{\mathrm{k}} \ldots \mathrm{I}_{18}^{\mathrm{k}}$ (different families). In a variant of the standard model of heterogeneous environments all individuals older than 18 receive the same skill investment of 1 until the rest of their lives. Thus, from period 18 on the marginal rate of skill production will not be smaller for the high percentiles compared to the first scenario with heterogeneous societies, but the individual rate of return to tertiary education changes as can be seen by comparing table 8 to table 7. Due to skill complementarities, people with a higher skill level benefit slightly more from an impulse even though higher percentiles still have a significantly high level of skills.

Table 8: Individual returns to education for the percentiles for heterogeneous families

\begin{tabular}{|c|c|c|c|c|}
\hline Percentile & $\begin{array}{c}\text { Impulse } \\
\mathrm{I}_{0}^{\mathrm{k}} \text { to } \mathrm{I}_{5}^{\mathrm{k}}\end{array}$ & $\begin{array}{c}\text { Impulse } \\
\mathrm{I}_{6}^{\mathrm{k}} \text { to } \mathrm{I}_{11}^{\mathrm{k}}\end{array}$ & $\begin{array}{c}\text { Impulse } \\
\mathrm{I}_{12}^{\mathrm{k}} \text { to } \mathrm{I}_{17}^{\mathrm{k}}\end{array}$ & $\begin{array}{c}\text { Impulse } \\
\mathrm{I}_{18}^{\mathrm{k}} \text { to } \mathrm{I}_{21}^{\mathrm{k}}\end{array}$ \\
\hline $1 \%$ & $27.59 \%$ & $18.09 \%$ & $4.81 \%$ & $-1.79 \%$ \\
\hline $10 \%$ & $17.78 \%$ & $11.94 \%$ & $3.83 \%$ & $0.04 \%$ \\
\hline $25 \%$ & $14.13 \%$ & $9.58 \%$ & $3.23 \%$ & $0.42 \%$ \\
\hline $50 \%$ & $11.70 \%$ & $7.99 \%$ & $2.78 \%$ & $0.62 \%$ \\
\hline $75 \%$ & $10.02 \%$ & $6.88 \%$ & $2.45 \%$ & $0.73 \%$ \\
\hline $90 \%$ & $8.87 \%$ & $6.12 \%$ & $2.21 \%$ & $0.79 \%$ \\
\hline $99 \%$ & $7.32 \%$ & $5.08 \%$ & $1.87 \%$ & $0.86 \%$ \\
\hline
\end{tabular}

The differences in the returns to education in tables 7 and 8 illustrate the importance of the decreasing marginal rate of return in the skill production function and of the small skill multiplier in adult age.

Tables 9 and 10 contain the results for the case when individuals differ, ceteris paribus, with respect to their ability of transforming a given educational input into new skills, $\delta$. This implies that individuals do not differ with respect to their environment. Decreasing marginal rates of education do not play a role in this scenario since the population of the seven individuals receives absolutely identical amounts of inputs from their environment. Now our findings for the returns to age-dependent education differ dramatically from the previous ones. 
Table 9: Returns to education in monetary units for the percentiles for heterogeneous giftedness (discounted to period 18)

\begin{tabular}{|c|c|c|c|c|}
\hline Percentile & $\begin{array}{c}\text { Impulse } \\
\mathrm{I}_{0}^{\mathrm{k}} \text { to } \mathrm{I}_{5}^{\mathrm{k}}\end{array}$ & $\begin{array}{c}\text { Impulse } \\
\mathrm{I}_{6}^{\mathrm{k}} \text { to } \mathrm{I}_{11}^{\mathrm{k}}\end{array}$ & $\begin{array}{c}\text { Impulse } \\
\mathrm{I}_{12}^{\mathrm{k}} \text { to } \mathrm{I}_{17}^{\mathrm{k}}\end{array}$ & $\begin{array}{c}\text { Impulse } \\
\mathrm{I}_{18}^{\mathrm{k}} \text { to } \mathrm{I}_{21}^{\mathrm{k}}\end{array}$ \\
\hline $1 \%$ & $-8612 €$ & $-17014 €$ & $-27574 €$ & $-23681 €$ \\
\hline $10 \%$ & $204569 €$ & $118570 €$ & $20716 €$ & $-12774 €$ \\
\hline $25 \%$ & $453737 €$ & $277156 €$ & $76232 €$ & $1572 €$ \\
\hline $50 \%$ & $773887 €$ & $481201 €$ & $146909 €$ & $20597 €$ \\
\hline $75 \%$ & $1141632 €$ & $715916 €$ & $227574 €$ & $42785 €$ \\
\hline $90 \%$ & $1517412 €$ & $956106 €$ & $309634 €$ & $65645 €$ \\
\hline $99 \%$ & $2312452 €$ & $1465226 €$ & $482454 €$ & $114315 €$ \\
\hline
\end{tabular}

Table 10: Individual returns to education for the percentiles for heterogeneous giftedness

\begin{tabular}{|c|c|c|c|c|}
\hline Percentile & $\begin{array}{l}\text { Impulse } \\
\mathrm{I}_{0}^{\mathrm{k}} \text { to } \mathrm{I}_{5}^{\mathrm{k}}\end{array}$ & $\begin{array}{c}\text { Impulse } \\
\mathrm{I}_{6}^{\mathrm{k}} \text { to } \mathrm{I}_{11}^{\mathrm{k}}\end{array}$ & $\begin{array}{c}\text { Impulse } \\
\mathrm{I}_{12}^{\mathrm{k}} \text { to } \mathrm{I}_{17}^{\mathrm{k}}\end{array}$ & $\begin{array}{c}\text { Impulse } \\
\mathrm{I}_{18}^{\mathrm{k}} \text { to } \mathrm{I}_{21}^{\mathrm{k}}\end{array}$ \\
\hline $1 \%$ & $-1.10 \%$ & $-2.23 \%$ & $-3.75 \%$ & $-4.73 \%$ \\
\hline $10 \%$ & $7.65 \%$ & $4.77 \%$ & $0.92 \%$ & $-0.88 \%$ \\
\hline $25 \%$ & $10.12 \%$ & $6.73 \%$ & $2.08 \%$ & $0.07 \%$ \\
\hline $50 \%$ & $11.70 \%$ & $7.99 \%$ & $2.78 \%$ & $0.62 \%$ \\
\hline $75 \%$ & $12.80 \%$ & $8.86 \%$ & $3.25 \%$ & $0.98 \%$ \\
\hline $90 \%$ & $13.57 \%$ & $9.48 \%$ & $3.56 \%$ & $1.22 \%$ \\
\hline $99 \%$ & $14.66 \%$ & $10.36 \%$ & $4.00 \%$ & $1.54 \%$ \\
\hline
\end{tabular}

The absolute and relative returns to education increase with giftedness. An investment in education has the highest returns for gifted individuals' and returns become lower or even negative for the others. Thus, differences in individual giftedness have a higher impact on inequality than differences stemming from the environment. This is a result of the basic properties of the technology of skill formation, selfproductivity and direct complementarities. Obviously, these findings have important policy implications. If the source of heterogeneity is varying it follows that individual abilities to transform educational inputs into new additional skills need more re- 
sources to be successful instead of compensating policies for environmental differences directed for instance to equity goals.

To summarize our findings so far: If our society of seven individuals wants to maximize the sum of the additional human capital formed by limited additional resources for investments in education, the best strategy is to either invest in students from a bright environment or with bright learning abilities. If the goal is the maximization of the relative returns to each individual, limited resources for additional educational investments should first be directed to the most disadvantaged in a world where the reason of heterogeneity is the environment. If heterogeneity stems form individual giftedness investments should again first be directed to the most gifted individuals.

\subsection{Returns to Asymmetric Investments in Skills}

It is possible that investments in skills are not symmetric. Therefore, we now assume that educational institutions can direct investments to enhance either cognitive or self-regulatory skills. Of course, due to the synergetic nature of learning, specific investments to foster one type of skills will indirectly also foster the other skills depending on the degree of complementarities. Knowledge about the most successful investment strategies for the different stages of childhood and adolescence is crucial for fostering human capital.

In the simulation model, an asymmetric skill investment of $\mathrm{I}_{\mathrm{t}}^{\mathrm{k}}=10$ is introduced into either cognitive or self-regulatory skills. Thus, the size of the skill investment is equal to the one of the previous chapter. We investigate the returns to education (cp. table 11 and 12) for a world where heterogeneity is caused by a variation in the environment $\left(\mathrm{I}_{0}^{\mathrm{k}} \ldots \mathrm{I}_{80}^{\mathrm{k}}\right)$. A striking result is that investments in cognitive skills in early childhood will have the highest long run impacts (table 11). In adolescence and young adult age, however, self-regulatory skill investments become the preferred type of investments (table 12). This result obviously depends on the relative magnitudes of the learning multipliers defined earlier together with the cumulative and synergetic nature of the technology of skill formation in our model. The selfregulatory learning multiplier was assumed to be lower than the cognitive multiplier before the age of 12 and higher afterwards.

By comparing the asymmetric skill impulse into cognitive skills (table 11) with the symmetric impulse (table 7) it can be seen that the symmetric impulse is always superior in early childhood which nicely illustrates the synergetic nature of skill formation. Lower levels of self-regulatory skills in early childhood weaken the strength of skill investments in later life due to skill complementarities, thus reducing the returns to education. For children from a bright environment the difference is small, but for children from disadvantaged environments the difference is larger. Especially for these children a mixed strategy therefore seems to be preferable. 
Table 11: Individual returns to education for a cognitive impulse (heterogeneous environment)

\begin{tabular}{|c|c|c|c|c|}
\hline Percentile & $\begin{array}{c}\text { Impulse } \\
\mathrm{I}_{0}^{\mathrm{k}} \text { to } \mathrm{I}_{5}^{\mathrm{k}}\end{array}$ & $\begin{array}{c}\text { Impulse } \\
\mathrm{I}_{6}^{\mathrm{k}} \text { to } \mathrm{I}_{11}^{\mathrm{k}}\end{array}$ & $\begin{array}{c}\text { Impulse } \\
\mathrm{I}_{12}^{\mathrm{k}} \text { to } \mathrm{I}_{17}^{\mathrm{k}}\end{array}$ & $\begin{array}{c}\text { Impulse } \\
\mathrm{I}_{18}^{\mathrm{k}} \text { to } \mathrm{I}_{21}^{\mathrm{k}}\end{array}$ \\
\hline $1 \%$ & $18.41 \%$ & $10.95 \%$ & $-0.90 \%$ & $-4.62 \%$ \\
\hline $10 \%$ & $13.95 \%$ & $8.88 \%$ & $0.91 \%$ & $-1.74 \%$ \\
\hline $25 \%$ & $11.81 \%$ & $7.68 \%$ & $1.08 \%$ & $-1.16 \%$ \\
\hline $50 \%$ & $10.23 \%$ & $6.75 \%$ & $1.10 \%$ & $-0.88 \%$ \\
\hline $75 \%$ & $9.07 \%$ & $6.05 \%$ & $1.06 \%$ & $-0.71 \%$ \\
\hline $90 \%$ & $8.23 \%$ & $5.53 \%$ & $1.02 \%$ & $-0.62 \%$ \\
\hline $99 \%$ & $7.03 \%$ & $4.78 \%$ & $0.93 \%$ & $-0.51 \%$ \\
\hline
\end{tabular}

By comparing the asymmetric self-regulatory skill impulse (table 12) with the symmetric skill impulse (table 7) it is obvious that there are periods where an asymmetric skill investment is superior. For children from a bright environment an asymmetric skill investment is superior for investments in secondary and tertiary education. For the others it is only superior for tertiary education. Children from a bright environment already receive enough cognitive skills and thus profit relatively more from an asymmetric impulse compared to a symmetric one. In young adult age, the returns to cognitive skill investment are already relatively low (in our model of skill formation).

Table 12: Individual returns to education for a self-regulatory impulse (heterogeneous societies)

\begin{tabular}{|c|c|c|c|c|}
\hline Percentile & $\begin{array}{c}\text { Impulse } \\
\mathrm{I}_{0}^{\mathrm{k}} \text { to } \mathrm{I}_{5}^{\mathrm{k}}\end{array}$ & $\begin{array}{c}\text { Impulse } \\
\mathrm{I}_{6}^{\mathrm{k}} \text { to } \mathrm{I}_{11}^{\mathrm{k}}\end{array}$ & $\begin{array}{c}\text { Impulse } \\
\mathrm{I}_{12}^{\mathrm{k}} \text { to } \mathrm{I}_{17}^{\mathrm{k}}\end{array}$ & $\begin{array}{c}\text { Impulse } \\
\mathrm{I}_{18}^{\mathrm{k}} \text { to } \mathrm{I}_{21}^{\mathrm{k}}\end{array}$ \\
\hline $1 \%$ & $8.13 \%$ & $5.05 \%$ & $2.23 \%$ & $-0.32 \%$ \\
\hline $10 \%$ & $7.17 \%$ & $5.01 \%$ & $2.98 \%$ & $1.16 \%$ \\
\hline $25 \%$ & $6.30 \%$ & $4.49 \%$ & $2.77 \%$ & $1.21 \%$ \\
\hline $50 \%$ & $5.58 \%$ & $4.01 \%$ & $2.52 \%$ & $1.15 \%$ \\
\hline $75 \%$ & $5.02 \%$ & $3.63 \%$ & $2.30 \%$ & $1.06 \%$ \\
\hline $90 \%$ & $4.60 \%$ & $3.34 \%$ & $2.13 \%$ & $0.98 \%$ \\
\hline $99 \%$ & $4.00 \%$ & $2.91 \%$ & $1.86 \%$ & $0.84 \%$ \\
\hline
\end{tabular}


To summarize our findings so far: A reasonable strategy for fostering human capital is to supply children with symmetric impulses in cognitive and self-regulatory skills until adolescence. In adult age more investments should be directed to improve selfregulatory skills.

\subsection{Individual Giftedness and Social Environment}

Hitherto, it was shown how the distribution of returns to education will depend on giftedness or the environment. This part investigates the consequences for returns to primary education with both factors of essential heterogeneity while also considering some aspects of the individual decision whether to attend tertiary education. We model a population where 50 percent of the heterogeneity of skills is explained by different environments and 50 percent by giftedness for example through genetic endowments (some authors argue that genetic endowment is responsible for 50 percent of the variation in IQs, for instance Weinert (2001)).

Both factors together cause an individual to belong to a specific percentile of the skills distribution. The population consists of 49 heterogeneous individuals reflecting all possible combinations of environmental and giftedness variations. Table 13 and 14 depict the absolute monetary as well as the individual relative returns to education of the primary school impulse for this population. The highest returns measured in absolute monetary units are achieved by the most gifted individuals who received the highest education in their social environment. However, the highest individual returns to an educational impulse are achieved by individuals with a high giftedness coming from disadvantaged environments.

Table 13: Monetary returns to education for heterogeneous giftedness and

families, discounted to period 18

\begin{tabular}{|c|c|c|c|c|c|c|c|c|}
\hline & & \multicolumn{7}{|c|}{ Giftedness } \\
\hline \multirow{4}{*}{} & Percentiles & $1 \%$ & $10 \%$ & $25 \%$ & $50 \%$ & $75 \%$ & $90 \%$ & $99 \%$ \\
\cline { 2 - 8 } & $1 \%$ & $192761 €$ & $528034 €$ & $723242 €$ & $879665 €$ & $1000000 €$ & $1090000 €$ & $1220000 €$ \\
\cline { 2 - 9 } & $10 \%$ & $212571 €$ & $628308 €$ & $878758 €$ & $1080000 €$ & $1240000 €$ & $1360000 €$ & $1540000 €$ \\
\cline { 2 - 9 } & $25 \%$ & $224759 €$ & $692995 €$ & $980378 €$ & $1220000 €$ & $1400000 €$ & $1540000 €$ & $1740000 €$ \\
\cline { 2 - 9 } & $50 \%$ & $235924 €$ & $754169 €$ & $1080000 €$ & $1340000 €$ & $1550000 €$ & $1710000 €$ & $1950000 €$ \\
\cline { 2 - 9 } & $75 \%$ & $245940 €$ & $810567 €$ & $1170000 €$ & $1460000 €$ & $1700000 €$ & $1870000 €$ & $2130000 €$ \\
\cline { 2 - 8 } & $90 \%$ & $254462 €$ & $859642 €$ & $1250000 €$ & $1570000 €$ & $1820000 €$ & $2010000 €$ & $2300000 €$ \\
\cline { 2 - 8 } & $99 \%$ & $269261 €$ & $947191 €$ & $1390000 €$ & $1760000 €$ & $2050000 €$ & $2270000 €$ & $2600000 €$ \\
\hline
\end{tabular}

Next we investigate the decision of choosing the optimal duration of tertiary education for the population of the 49 individuals, e.g. attending bachelor or master pro- 
grammes in a university. Individuals will maximize their returns to education considering the trade off between higher lifetime earnings caused by additional skill formation and its costs (foregone earnings, educational costs). Table 15 contains the optimal time of attending university which each individual from our population chooses. Two factors drive the decision of how long to attend university. First, gifted students will accumulate skills more easily starting already in early childhood and thus perceive a higher benefit from attending tertiary education.

Table 14: Individual returns to education for heterogeneous giftedness and families

\begin{tabular}{|c|c|c|c|c|c|c|c|c|}
\hline \multicolumn{2}{|c|}{} & \multicolumn{7}{c|}{ Giftedness } \\
\hline \multirow{3}{*}{} & Percentiles & $1 \%$ & $10 \%$ & $25 \%$ & $50 \%$ & $75 \%$ & $90 \%$ & $99 \%$ \\
\cline { 2 - 9 } & $1 \%$ & $1.34 \%$ & $8.75 \%$ & $10.56 \%$ & $11.60 \%$ & $12.24 \%$ & $12.67 \%$ & $13.19 \%$ \\
\cline { 2 - 9 } & $10 \%$ & $1.01 \%$ & $7.37 \%$ & $8.84 \%$ & $9.64 \%$ & $10.19 \%$ & $10.54 \%$ & $11.04 \%$ \\
\cline { 2 - 9 } & $25 \%$ & $0.84 \%$ & $6.68 \%$ & $7.99 \%$ & $8.80 \%$ & $9.20 \%$ & $9.51 \%$ & $9.84 \%$ \\
\cline { 2 - 9 } & $50 \%$ & $0.70 \%$ & $6.13 \%$ & $7.37 \%$ & $7.94 \%$ & $8.37 \%$ & $8.73 \%$ & $9.13 \%$ \\
\cline { 2 - 9 } & $75 \%$ & $0.60 \%$ & $5.70 \%$ & $6.84 \%$ & $7.37 \%$ & $7.75 \%$ & $8.04 \%$ & $8.37 \%$ \\
\cline { 2 - 9 } & $90 \%$ & $0.52 \%$ & $5.37 \%$ & $6.45 \%$ & $6.98 \%$ & $7.24 \%$ & $7.44 \%$ & $7.80 \%$ \\
\cline { 2 - 8 } & $99 \%$ & $0.40 \%$ & $4.87 \%$ & $5.81 \%$ & $6.32 \%$ & $6.59 \%$ & $6.83 \%$ & $7.06 \%$ \\
\hline
\end{tabular}

Secondly, students from more favourable environments achieve higher gains from attending university. They tend to remain in university for a longer time even though facing the opportunity cost of not being able to work during this time.

Table 15: Utility maximizing duration of tertiary education in years

\begin{tabular}{|c|c|c|c|c|c|c|c|c|}
\hline & & \multicolumn{7}{|c|}{ Giftedness } \\
\hline \multirow{4}{*}{} & Percentiles & $1 \%$ & $10 \%$ & $25 \%$ & $50 \%$ & $75 \%$ & $90 \%$ & $99 \%$ \\
\cline { 2 - 9 } & $1 \%$ & 0 & 0 & 1 & 2 & 3 & 4 & 4 \\
\cline { 2 - 9 } & $10 \%$ & 0 & 0 & 2 & 3 & 4 & 5 & 5 \\
\cline { 2 - 9 } & $25 \%$ & 0 & 1 & 2 & 4 & 4 & 5 & 5 \\
\cline { 2 - 9 } & $50 \%$ & 0 & 1 & 3 & 4 & 5 & 5 & 6 \\
\cline { 2 - 9 } & $75 \%$ & 0 & 1 & 3 & 4 & 5 & 5 & 6 \\
\cline { 2 - 9 } & $90 \%$ & 0 & 2 & 3 & 4 & 5 & 5 & 6 \\
\cline { 2 - 9 } & $99 \%$ & 0 & 2 & 4 & 5 & 5 & 6 & 6 \\
\hline
\end{tabular}




\subsection{Life Expectancy and Returns to Education}

In this chapter we examine the possible influence of rising life expectancy and potential working life duration observed in most industrial countries for the distribution of age-dependent returns to education. For that goal we assume that an individual's earnings stream starts at the age of 18 and continues until death. Two scenarios are compared. In the first scenario individuals live 80 years and in the second they live 90 years. We assess the distribution of the returns to education for a preschool impulse, a primary impulse, a secondary and a tertiary impulse as in our previous analysis as well and for both life expectancies. Tables 16 and 17 contain the changes in the returns to education if life expectancy increases from 80 to 90 years while assuming that the heterogeneity of skills arises from the environment.

Table 16: Change in returns to education in monetary units if life expectancy increases from 80 to 90 years (heterogeneous families, discounted to period 18)

\begin{tabular}{|c|c|c|c|c|}
\hline Percentile & $\begin{array}{c}\text { Impulse } \\
\mathrm{I}_{0}^{\mathrm{k}} \text { to } \mathrm{I}_{5}^{\mathrm{k}}\end{array}$ & $\begin{array}{c}\text { Impulse } \\
\mathrm{I}_{6}^{\mathrm{k}} \text { to } \mathrm{I}_{11}^{\mathrm{k}}\end{array}$ & $\begin{array}{c}\text { Impulse } \\
\mathrm{I}_{12}^{\mathrm{k}} \text { to } \mathrm{I}_{17}^{\mathrm{k}}\end{array}$ & $\begin{array}{c}\text { Impulse } \\
\mathrm{I}_{18}^{\mathrm{k}} \text { to } \mathrm{I}_{21}^{\mathrm{k}}\end{array}$ \\
\hline $1 \%$ & $+282195 €$ & $+161569 €$ & $+46162 €$ & $+7530 €$ \\
\hline $10 \%$ & $+335462 €$ & $+209281 €$ & $+69445 €$ & $+16836 €$ \\
\hline $25 \%$ & $+358527 €$ & $+231127 €$ & $+81050 €$ & $+23997 €$ \\
\hline $50 \%$ & $+375771 €$ & $+247731 €$ & $+90161 €$ & $+31409 €$ \\
\hline $75 \%$ & $+389140 €$ & $+260620 €$ & $+97350 €$ & $+38690 €$ \\
\hline $90 \%$ & $+399390 €$ & $+270470 €$ & $+102850 €$ & $+45310 €$ \\
\hline $99 \%$ & $+415610 €$ & $+285840 €$ & $+111430 €$ & $+57720 €$ \\
\hline
\end{tabular}

For each student of our population, higher life expectancy improves the returns to education. Not surprisingly, the absolute monetary returns to education increase the most the earlier additional investments takes place. Furthermore, due to skill complementarities, early investments for students from bright environments will generate more human capital than for students from disadvantaged environments. However, table 17 reveals the opposite picture for individual relative returns to education. These are the lower the brighter students already are. But the new finding is that these returns increase with age. So if it is not possible for whatever reasons to invest during early childhood, higher life expectancy seems to enhance the returns of tertiary education specifically for students from disadvantaged environments. The relative gains from tertiary instead of primary additional education seem to be the higher the longer life expectancy lasts.

Now we assume that the reason for heterogeneous skills arises from giftedness. The simulation results in Table 18 indicate that in this dimension of heterogeneity abso- 
lute returns to education vary to a higher degree. The increase in human capital for disadvantaged students is quite low even for very early education while gifted students receive an increase of 1,132,800 $€$ if their life expectancy rises by ten years and if they receive a six year lasting additional preschool investment.

Table17: Change in individual returns to education in percentage points if life expectancy increases from 80 to 90 years (heterogeneous families, discounted to period 18)

\begin{tabular}{|c|c|c|c|c|}
\hline Percentile & $\begin{array}{c}\text { Impulse } \\
\mathrm{I}_{0}^{\mathrm{k}} \text { to } \mathrm{I}_{5}^{\mathrm{k}}\end{array}$ & $\begin{array}{c}\text { Impulse } \\
\mathrm{I}_{6}^{\mathrm{k}} \text { to } \mathrm{I}_{11}^{\mathrm{k}}\end{array}$ & $\begin{array}{c}\text { Impulse } \\
\mathrm{I}_{12}^{\mathrm{k}} \text { to } \mathrm{I}_{17}^{\mathrm{k}}\end{array}$ & $\begin{array}{c}\text { Impulse } \\
\mathrm{I}_{18}^{\mathrm{k}} \text { to } \mathrm{I}_{21}^{\mathrm{k}}\end{array}$ \\
\hline $1 \%$ & $+0.27 \%$ & $+0.55 \%$ & $+0.82 \%$ & $+1.09 \%$ \\
\hline $10 \%$ & $+0.15 \%$ & $+0.29 \%$ & $+0.38 \%$ & $+0.55 \%$ \\
\hline $25 \%$ & $+0.11 \%$ & $+0.21 \%$ & $+0.27 \%$ & $+0.42 \%$ \\
\hline $50 \%$ & $+0.09 \%$ & $+0.17 \%$ & $+0.20 \%$ & $+0.35 \%$ \\
\hline $75 \%$ & $+0.07 \%$ & $+0.14 \%$ & $+0.17 \%$ & $+0.31 \%$ \\
\hline $90 \%$ & $+0.06 \%$ & $+0.12 \%$ & $+0.14 \%$ & $+0.29 \%$ \\
\hline $99 \%$ & $+0.05 \%$ & $+0.09 \%$ & $+0.11 \%$ & $+0.25 \%$ \\
\hline
\end{tabular}

Table 18: Change in returns to education in monetary units if life expectancy increases from 80 to 90 years, heterogeneous giftedness, discounted to period 18

\begin{tabular}{|c|c|c|c|c|}
\hline Percentile & $\begin{array}{c}\text { Impulse } \\
\mathrm{I}_{0}^{\mathrm{k}} \text { to } \mathrm{I}_{5}^{\mathrm{k}}\end{array}$ & $\begin{array}{c}\text { Impulse } \\
\mathrm{I}_{6}^{\mathrm{k}} \text { to } \mathrm{I}_{11}^{\mathrm{k}}\end{array}$ & $\begin{array}{c}\text { Impulse } \\
\mathrm{I}_{12}^{\mathrm{k}} \text { to } \mathrm{I}_{17}^{\mathrm{k}}\end{array}$ & $\begin{array}{c}\text { Impulse } \\
\mathrm{I}_{18}^{\mathrm{k}} \text { to } \mathrm{I}_{21}^{\mathrm{k}}\end{array}$ \\
\hline $1 \%$ & $+14657 €$ & $+9751 €$ & $+3776 €$ & $+1219 €$ \\
\hline $10 \%$ & $+108270 €$ & $+71547 €$ & $+26756 €$ & $+9356 €$ \\
\hline $25 \%$ & $+223628 €$ & $+147528 €$ & $+54316 €$ & $+18988 €$ \\
\hline $50 \%$ & $+375771 €$ & $+247731 €$ & $+90161 €$ & $+31409 €$ \\
\hline $75 \%$ & $+553720 €$ & $+364980 €$ & $+131680 €$ & $+45690 €$ \\
\hline $90 \%$ & $+737890 €$ & $+486420 €$ & $+174390 €$ & $+60290 €$ \\
\hline $99 \%$ & $+1132800 €$ & $+747130 €$ & $+265370 €$ & $+91200 €$ \\
\hline
\end{tabular}

For individual returns to education table 19 reveals a different picture. These returns are the smaller the brighter students already are and they tend to increase with age for all students. So if it is not possible for whatever reason to invest additional resources in early childhood, increased life expectancy leads to an higher returns to 
tertiary education for low ability students as well. However, there is no difference in the rate of returns between early and later investments.

Table 19: Change in individual returns to education in percentage points if life expectancy rises from 80 to 90 years (heterogeneous giftedness, discounted to period 18)

\begin{tabular}{|c|c|c|c|c|}
\hline Percentile & $\begin{array}{c}\text { Impulse } \\
\mathrm{I}_{0}^{\mathrm{k}} \text { to } \mathrm{I}_{5}^{\mathrm{k}}\end{array}$ & $\begin{array}{c}\text { Impulse } \\
\mathrm{I}_{6}^{\mathrm{k}} \text { to } \mathrm{I}_{11}^{\mathrm{k}}\end{array}$ & $\begin{array}{c}\text { Impulse } \\
\mathrm{I}_{12}^{\mathrm{k}} \text { to } \mathrm{I}_{17}^{\mathrm{k}}\end{array}$ & $\begin{array}{c}\text { Impulse } \\
\mathrm{I}_{18}^{\mathrm{k}} \text { to } \mathrm{I}_{21}^{\mathrm{k}}\end{array}$ \\
\hline $1 \%$ & $+1.38 \%$ & $+1.33 \%$ & $+1.28 \%$ & $+1.34 \%$ \\
\hline $10 \%$ & $+0.35 \%$ & $+0.40 \%$ & $+0.44 \%$ & $+0.59 \%$ \\
\hline $25 \%$ & $+0.17 \%$ & $+0.25 \%$ & $+0.28 \%$ & $+0.44 \%$ \\
\hline $50 \%$ & $+0.09 \%$ & $+0.17 \%$ & $+0.20 \%$ & $+0.35 \%$ \\
\hline $75 \%$ & $+0.04 \%$ & $+0.12 \%$ & $+0.16 \%$ & $+0.30 \%$ \\
\hline $90 \%$ & $+0.00 \%$ & $+0.09 \%$ & $+0.13 \%$ & $+0.27 \%$ \\
\hline $99 \%$ & $-0.04 \%$ & $+0.05 \%$ & $+0.10 \%$ & $+0.23 \%$ \\
\hline
\end{tabular}

\subsection{Wage Inequality and Returns to Education}

In part 4.3., the effect of the labour market on human capital inequality was introduced. In this chapter we consider the relationship between wage inequality and the returns to education which has been researched intensively in empirical work in recent years (see for instance Autor et al. (2006), or Gernandt and Pfeiffer (2006) for Germany). We assume heterogeneous skills due to heterogeneous family environments and adjust wage inequality to the level of three different countries. Educational levels in these countries are calibrated to the German PISA 2000 reading results.

The degree of inequalities in wages is caused by differences in labour markets and not by differences in skills. The first country has a 90-10 ratio of 1.89 and thus a relatively small wage inequality, the second country has a 90-10 ratio of 3 like in Germany and the third country a relatively high inequality in earnings with a 90-10 ratio of 7 which is halfway between the United States of America and India, for instance. Table 20 summarizes the discounted lifetime human capital for the 7 different percentiles in each of the three countries. Note that the 90-10 ratios of the discounted lifetime earnings differ slightly from the actual 90-10 ratios. 
The numbers in table 20 illustrate the difference in human capital arising from the modelled labour market institutions given that the heterogeneity of skills is the same in each country.

Table 20: Discounted lifetime earnings for countries differing in wage inequality

\begin{tabular}{|c|c|c|c|}
\hline Percentile & $\begin{array}{c}\text { Country 1: } \\
90-10 \text { ratio: } 1.89\end{array}$ & $\begin{array}{c}\text { Country 2: } \\
90-10 \text { ratio: } 3\end{array}$ & $\begin{array}{c}\text { Country 3: } \\
90-10 \text { ratio: } 7\end{array}$ \\
\hline $1 \%$ & $351,669 €$ & $173,398 €$ & $48,998 €$ \\
\hline $10 \%$ & $574,307 €$ & $411,957 €$ & $229,699 €$ \\
\hline $25 \%$ & $716,921 €$ & $608,674 €$ & $459,777 €$ \\
\hline $50 \%$ & $850,153 €$ & $821,275 €$ & $782,304 €$ \\
\hline $75 \%$ & $971,188 €$ & $1,037,480 €$ & $1,183,550 €$ \\
\hline $90 \%$ & $1,075,090 €$ & $1,239,980 €$ & $1,622,730 €$ \\
\hline $99 \%$ & $1,256,930 €$ & $1,630,690 €$ & $2,633,750 €$ \\
\hline
\end{tabular}

Table 21: Individual rates of return for a preschool impulse with a duration of 6 years

\begin{tabular}{|c|c|c|c|}
\hline Percentile & $\begin{array}{c}\text { Country 1: } \\
90-10 \text { ratio }: 1.89\end{array}$ & $\begin{array}{c}\text { Country 2: } \\
90-10 \text { ratio : } 3\end{array}$ & $\begin{array}{c}\text { Country 3: } \\
90-10 \text { ratio : } 7\end{array}$ \\
\hline $1 \%$ & $14.65 \%$ & $27.59 \%$ & $54.27 \%$ \\
\hline $10 \%$ & $9.52 \%$ & $17.78 \%$ & $33.91 \%$ \\
\hline $25 \%$ & $7.58 \%$ & $14.13 \%$ & $26.66 \%$ \\
\hline $50 \%$ & $6.26 \%$ & $11.70 \%$ & $21.89 \%$ \\
\hline $75 \%$ & $5.35 \%$ & $10.02 \%$ & $18.66 \%$ \\
\hline $90 \%$ & $4.73 \%$ & $8.87 \%$ & $16.45 \%$ \\
\hline $99 \%$ & $3.88 \%$ & $7.32 \%$ & $13.50 \%$ \\
\hline
\end{tabular}

Tables 21 and 22 contain the individual rates of return from the preschool impulse for the three countries and the returns from a tertiary school impulse, respectively. The major result that can be drawn from table 21 is that rising labour market inequality increases the returns to education significantly. The incentive to invest in additional education rises when people plan to enter a labour market with a high skill premium. Table 22 shows that if labour market inequality is too small, no incentive persists to invest in a tertiary education in country 1 . The additional gain in human capital from further skills is below the costs of education. 
Table 22: Individual rates of return for a tertiary school impulse with a duration of 4 years

\begin{tabular}{|c|c|c|c|}
\hline Percentile & $\begin{array}{c}\text { Country 1: } \\
90-10 \text { ratio }: 1.89\end{array}$ & $\begin{array}{c}\text { Country 2: } \\
90-10 \text { ratio }: 3\end{array}$ & $\begin{array}{c}\text { Country 3: } \\
90-10 \text { ratio }: 7\end{array}$ \\
\hline $1 \%$ & $-1.63 \%$ & $-1.79 \%$ & $-7.90 \%$ \\
\hline $10 \%$ & $-0.97 \%$ & $0.04 \%$ & $1.34 \%$ \\
\hline $25 \%$ & $-0.77 \%$ & $0.42 \%$ & $2.33 \%$ \\
\hline $50 \%$ & $-0.65 \%$ & $0.62 \%$ & $2.67 \%$ \\
\hline $75 \%$ & $-0.57 \%$ & $0.73 \%$ & $2.81 \%$ \\
\hline $90 \%$ & $-0.52 \%$ & $0.79 \%$ & $2.86 \%$ \\
\hline $99 \%$ & $-0.45 \%$ & $0.86 \%$ & $2.88 \%$ \\
\hline
\end{tabular}

\subsection{An Alternative Learning Multiplier for Self-regulatory Skills}

In this section we discuss findings from a model with a different self-regulatory skill learning multiplier. We now assume that infancy is more relevant for self-regulatory compared to cognitive skill development, see Figure 9 for the new learning multiplier $l_{t}^{\mathrm{N}}$.

Figure 9: Alternative self-regulatory learning multiplier from age 0 to 30

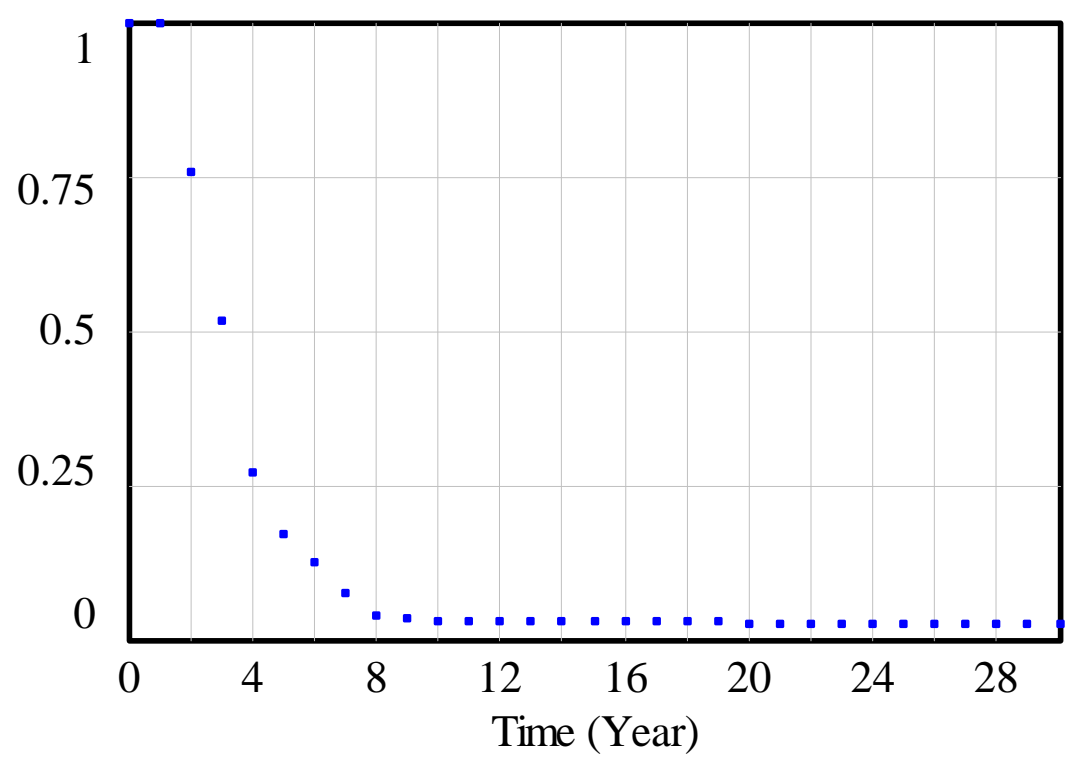


The new pattern of self-regulatory skill development over the life cycle from this learning multiplier (put into equations (9) and (10)) for our standard individual is illustrated in figure 10. Using the new multiplier self-regulatory skills grow more rapidly during infancy and exceed the growth of cognitive until the age of about 10 years. Cognitive skills surpass self-regulatory skills in late childhood and adolescence until the age of about 35. In mid to old age the loss of cognitive skills is then compensated by self-regulatory skills as in our standard model (see e.g. chapter 4.1.). This also results in a change of returns to education. Table 23 summarizes the individual returns to education if heterogeneity arises from different families.

Figure 10: Cognitive skills (blue) and self-regulatory skills (red) from age 0 to 80

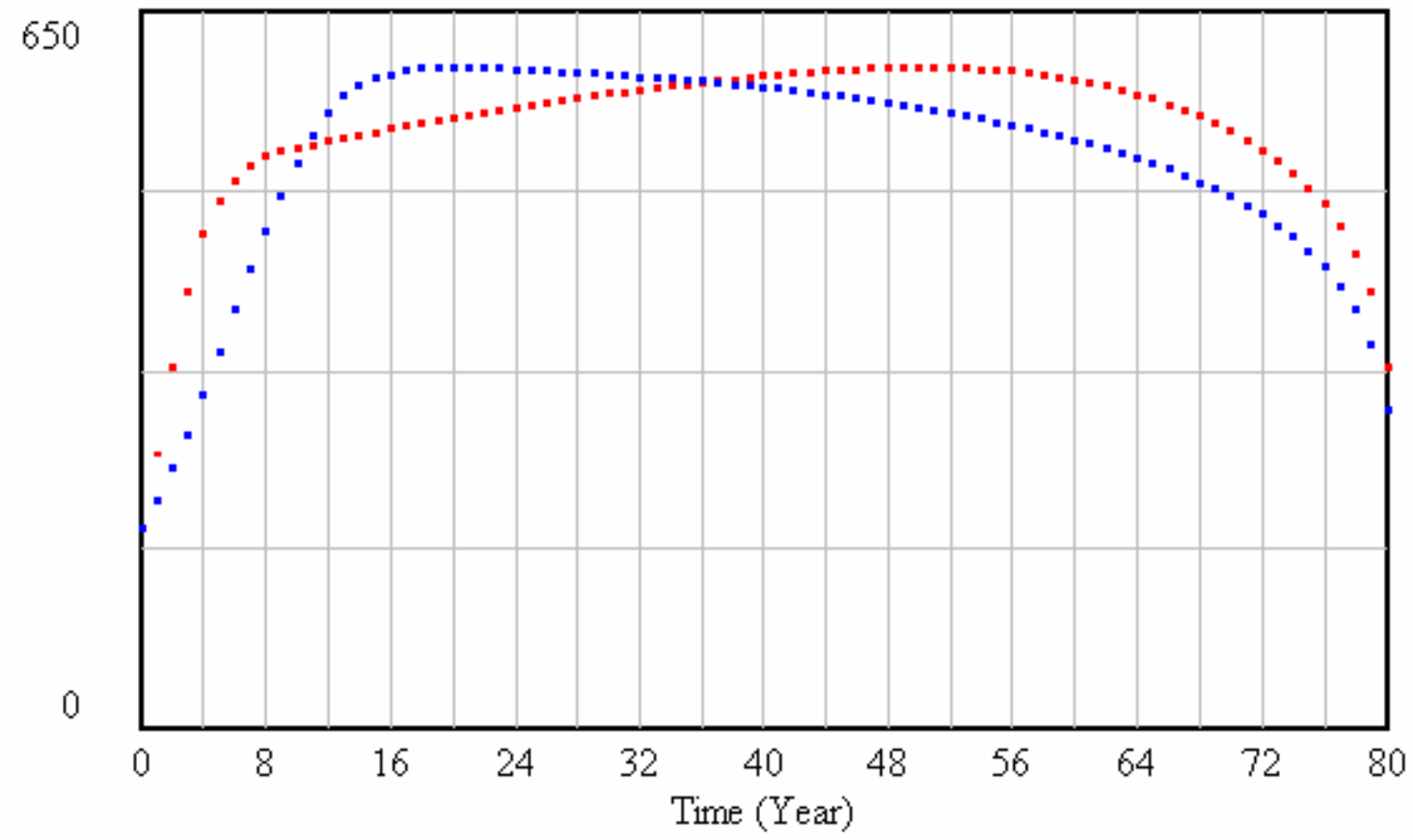

Table 23: Individual returns to education in monetary units for the percentiles in heterogeneous families in the modified model (discounted to period 18)

\begin{tabular}{|c|c|c|c|c|}
\hline Percentile & $\begin{array}{c}\text { Impulse } \\
\mathrm{I}_{0}^{\mathrm{k}} \text { to } \mathrm{I}_{5}^{\mathrm{k}}\end{array}$ & $\begin{array}{c}\text { Impulse } \\
\mathrm{I}_{6}^{\mathrm{k}} \text { to } \mathrm{I}_{11}^{\mathrm{k}}\end{array}$ & $\begin{array}{c}\text { Impulse } \\
\mathrm{I}_{12}^{\mathrm{k}} \text { to } \mathrm{I}_{17}^{\mathrm{k}}\end{array}$ & $\begin{array}{c}\text { Impulse } \\
\mathrm{I}_{18}^{\mathrm{k}} \text { to } \mathrm{I}_{21}^{\mathrm{k}}\end{array}$ \\
\hline $1 \%$ & $41.50 \%$ & $9.41 \%$ & $0.03 \%$ & $-3.44 \%$ \\
\hline $10 \%$ & $27.16 \%$ & $6.77 \%$ & $0.78 \%$ & $-1.58 \%$ \\
\hline $25 \%$ & $21.80 \%$ & $5.60 \%$ & $0.80 \%$ & $-1.16 \%$ \\
\hline $50 \%$ & $18.17 \%$ & $4.76 \%$ & $0.76 \%$ & $-0.93 \%$ \\
\hline $75 \%$ & $15.62 \%$ & $4.15 \%$ & $0.70 \%$ & $-0.79 \%$ \\
\hline $90 \%$ & $13.88 \%$ & $3.72 \%$ & $0.66 \%$ & $-0.71 \%$ \\
\hline $99 \%$ & $11.50 \%$ & $3.12 \%$ & $0.58 \%$ & $-0.61 \%$ \\
\hline
\end{tabular}


In comparison to the results from section one above a pre-school impulse gains significant importance in term of higher returns to education for all individuals. Returns to tertiary education turn even into negative numbers due to the opportunity cost of education, the fact that individuals can only start working and winning money 4 years later. If infancy dominates the formation of self-regulatory competences as well as of cognitive skills in the way discussed, investment into skills in adult life do not enhance human capital. This however doesn't contradict the fact that tertiary education obviously yields returns. E.g. we do not model the effects of signalling or a dynamic labour market. Tertiary education may also be more important in the case of higher wage inequalities. What persists in both models is the fact that low percentiles gain higher individual returns to education but smaller monetary returns. Also returns to education decrease with age.

To sum up with the model modification the preschool impulse gains significant importance relative to all later educational impulses. These results imply that if infancy is a critical period not only for cognitive skills, but also for self-regulatory skills, pre-school investments into skills are even more important. For children from disadvantaged environments for instance such additional pre-school investments are the only way to help them to enhance theirs level of skills and human capital. Even though self-regulatory skills can increase more easily in adult age than cognitive skills, reflecting the results described in chapter 2.2., an unfavourable environment in infancy decreases the stability of personality dramatically.

\section{Efficiency and Equity}

\subsection{Inequality and the Welfare Function}

In this chapter we will use the Atkinson index and a welfare function for considering some aspects of the trade off between efficiency and equity in educational policies for the life cycle welfare of our population of seven individuals. We assume the standard model of life cycle skill formation as introduced in chapter 4. The Atkinson Index (Atkinson (1970)) is a discrete measure of inequality for an income distribution of a population with $\mathrm{N}$ individuals:

$$
A_{\varepsilon}(Y)=1-\left[\frac{1}{N} \sum_{i=1}^{N}\left(\frac{y_{i}}{\mu}\right)^{1-\varepsilon}\right]^{\frac{1}{1-\varepsilon}}
$$

$y_{i}$ symbolizes individual human capital accumulated over the life span, $\mu$ the average human capital of the population and $\varepsilon$ is a parameter for indicating different degrees of equity preferences in the society. For $\varepsilon=0$, a society does not care about equity at all. For $\varepsilon=\infty$, the index only depends on the welfare of the poorest indi- 
vidual of the society. The Atkinson Index is normalized between 0 and 1 . If $A_{\varepsilon}(Y)=0$, there exists no measured inequality in the distribution while $A_{\varepsilon}(Y)=1$ indicates maximum inequality. For empirical applications, equity considerations may vary between $0.5 \leq \varepsilon \leq 2.5$ (Atkinson (1970)). Based on this index, we employ the following welfare function for our population (Sen et al. (1997)):

$$
W(Y)=\left(1-A_{\varepsilon}(Y)\right) \cdot \sum_{i=1}^{N} y_{i}
$$

We will use the Atkinson index (equation 20) and the welfare function (equation 21) for assessing the impact of various educational policies on the welfare of our population of seven individuals for different values of $\varepsilon$. Educational policies are restricted by exogenous scarcity and the welfare maximizing plan of the policy maker. Scarcity is modelled in a simple way. We assume that only 3 out of the 7 individuals of our population can receive an additional educational investment. Four different investment policies are available. Policy makers are interested in a comparison of additional preschool and tertiary investment in skills. Based on our simulation model, we assess the optimal allocation of educational investments for maximizing welfare. First we consider the case where heterogeneity in adult life arises from different family environments in childhood.

Table 24 shows the amount of inequality measured by the Atkinson index for four different allocations, see column 1 . As $\varepsilon$ rises, the index becomes more sensitive to inequality. Compensating policies defined as preschool investments for the most disadvantaged students reduce the Atkinson index for various values of $\varepsilon$. With additional investments in skills during young adulthood, the Atkinson does not change that much. For equity reasons, educational investments should be directed to early childhood in a society where the heterogeneity of skills stems from the social environment (see also Armor (2003), Cunha et al. (2006)). In general, additional education for students from advantaged environments increases inequality.

Table 25 shows the welfare resulting from the 4 different allocations. As $\varepsilon$ rises, inequality is perceived more critically and thus reduces welfare. On the other side, for $\varepsilon=0$ inequality does not reduce welfare at all. Welfare is equal to the sum of the accumulated human capital of the members of the population. The tertiary impulse produces less welfare than the preschool impulse due to a much smaller learning multiplier in adult age and due to skill complementarities. Human capital accumulation is maximized when the scarce resources are invested in students from advantaged environments. The more important equity considerations become in a society, the more compensating educational policies are required for welfare maximization (at least in the absence of social transfer policies which are discussed in the next section of this chapter). 
Table 24: Atkinson indices for different allocations of education (heterogeneous families)

\begin{tabular}{|c|c|c|c|c|}
\hline & $\varepsilon=0$ & $\varepsilon=0.5$ & $\varepsilon=2.5$ & $\varepsilon=100$ \\
\hline $\begin{array}{c}\text { No impulse } \\
\text { Percentiles receiving a preschool } \\
\text { impulse }\end{array}$ & 0 & 0.087 & 0.469 & 0.791 \\
\hline $1,10,25$ & 0 & 0.015 & 0.072 & 0.297 \\
\hline $10,25,50$ & 0 & 0.064 & 0.547 & 0.85 \\
\hline 25, 50, 75 & 0 & 0.095 & 0.589 & 0.852 \\
\hline $75,90,99$ & 0 & 0.143 & 0.619 & 0.855 \\
\hline Percentiles receiving a tertiary & & & & \\
\hline impulse & & & & 0.782 \\
\hline $1,10,25$ & 0 & 0.082 & 0.451 & 0.794 \\
\hline 10, 25, 50 & 0 & 0.084 & 0.469 & 0.795 \\
\hline $75,90,99$ & 0 & 0.091 & 0.483 & 0.798 \\
\hline
\end{tabular}

Welfare maximization through the allocation of the preschool impulse is always achieved by investing in the lower percentiles except for cases where equity doesn't matter. For the tertiary impulse the picture is not so clear. Skill complementarities make investments in students from productive environments more profitable relative to the preschool impulse since the heterogeneity of skills is much larger later in life. Weather it is optimal to invest in high or low skilled students will crucially depend on the value of $\varepsilon$. Societies caring only little about income equality $(\varepsilon=0.5)$ maximize their welfare by investing in high skilled students even though this policy increases inequality. Societies caring more about equity $(\varepsilon=2.5)$ are better off by investing in low skilled students. In that case, the sum of human capital is lower, but inequality is lower as well.

In a second analysis it is now assumed that income heterogeneity results from giftedness. Table 26 displays the Atkinson indices for different allocations of education. In the case when heterogeneity results from giftedness, inequality is much larger. The Atkinson indices in table 26 are higher (closer to one) compared to table 24 Again, inequality can be influenced much better early in life. For the tertiary impulse, investing in low skilled students not always seems to be the best strategy for minimizing inequality since the impact of investing in the lowest skill percentiles is so small that inequality may even increase. For the preschool impulse this is not the 
case since skills are still more malleable at young age. Table 27 shows the welfare resulting from the different allocations.

Table 25: Welfare for different allocations of education (heterogeneous families)

\begin{tabular}{|c|c|c|c|c|}
\hline & $\varepsilon=0$ & $\varepsilon=0.5$ & $\varepsilon=2.5$ & $\varepsilon=100$ \\
\hline $\begin{array}{c}\text { No impulse } \\
\text { Percentiles receiving a preschool } \\
\text { impulse }\end{array}$ & $5923454 €$ & $5409830 €$ & $2633510 €$ & $1237880 €$ \\
\hline $1,10,25$ & $8060257 €$ & $7942168 €$ & $7483264 €$ & $5665527 €$ \\
\hline $10,25,50$ & $8259578 €$ & $7731012 €$ & $3743243 €$ & $1237880 €$ \\
\hline 25, 50, 75 & $8374675 €$ & $7576988 €$ & $3441390 €$ & $1237880 €$ \\
\hline $75,90,99$ & $8549374 €$ & $7331301 €$ & $3258487 €$ & $1237880 €$ \\
\hline Percentiles receiving a tertiary & & & & \\
\hline impulse & & & & \\
\hline $1,10,25$ & $5986552 €$ & $5494650 €$ & $3287546 €$ & $1304286 €$ \\
\hline $10,25,50$ & $6019252 €$ & $5515688 €$ & $3195423 €$ & $1237880 €$ \\
\hline $25,50,75$ & $6049279 €$ & $5530462 €$ & $3175237 €$ & $1237880 €$ \\
\hline $75,90,99$ & $6114744 €$ & $5555995 €$ & $3159739 €$ & $1237880 €$ \\
\hline
\end{tabular}

Table 26: Atkinson indices for different allocations of education (heterogeneous giftedness)

\begin{tabular}{|c|c|c|c|c|}
\hline & $\varepsilon=0$ & $\varepsilon=0.5$ & $\varepsilon=2.5$ & $\varepsilon=100$ \\
\hline $\begin{array}{c}\text { No impulse } \\
\begin{array}{c}\text { Percentiles receiving a preschool } \\
\text { impulse }\end{array}\end{array}$ & 0 & 0.110 & 0.570 & 0.843 \\
\hline $1,10,25$ & 0 & 0.077 & 0.502 & 0.823 \\
\hline $10,25,50$ & 0 & 0.087 & 0.617 & 0.875 \\
\hline 25, 50, 75 & 0 & 0.119 & 0.674 & 0.889 \\
\hline $75,90,99$ & & 0.209 & 0.758 & 0.915 \\
\hline $\begin{array}{c}\text { Percentiles receiving a tertiary } \\
\text { impulse }\end{array}$ & 0 & 0.108 & 0.574 & 0.847 \\
\hline $1,10,25$ & 0 & 0.107 & 0.571 & 0.845 \\
\hline $10,25,50$ & 0 & 0.109 & 0.576 & 0.846 \\
\hline $25,50,75$ & 0 & 0.117 & 0.589 & 0.85 \\
\hline $75,90,99$ & & & & \\
\hline
\end{tabular}


For the preschool impulse, welfare is maximized by investing in the most capable students for societies caring little about equality $(\varepsilon=0.5)$ and by investing in the most disadvantaged students for societies caring more about equity $(\varepsilon=2.5)$. For the tertiary impulse, basically the same strategy is optimal as for the preschool impulse. However, the $1^{\text {st }}$ percentile is so weak in accumulating skills due to skill complementarities such that a society with $\varepsilon=2.5$ maximizes welfare by only investing in the $10^{\text {th }}, 25^{\text {th }}$ and $50^{\text {th }}$ percentile.

Table 27: Welfare for different allocations of education (heterogeneous giftedness)

\begin{tabular}{|c|c|c|c|c|}
\hline & $\varepsilon=0$ & $\varepsilon=0.5$ & $\varepsilon=2.5$ & $\varepsilon=100$ \\
\hline $\begin{array}{c}\text { No impulse } \\
\text { Percentiles receiving a preschool } \\
\text { impulse }\end{array}$ & $6123024 €$ & $5452233 €$ & $2633510 €$ & $959896 €$ \\
\hline $1,10,25$ & $6911212 €$ & $6381070 €$ & $3442495 €$ & $1226222 €$ \\
\hline $10,25,50$ & $7692631 €$ & $7020010 €$ & $2944030 €$ & $959896 €$ \\
\hline $25,50,75$ & $8622144 €$ & $7600823 €$ & $2811825 €$ & $959896 €$ \\
\hline $75,90,99$ & $11233024 €$ & $8889667 €$ & $2714208 €$ & $959896 €$ \\
\hline $\begin{array}{c}\text { Percentiles receiving a tertiary } \\
\text { impulse }\end{array}$ & & & & \\
\hline $1,10,25$ & $6152356 €$ & $5485649 €$ & $2619466 €$ & $943648 €$ \\
\hline $10,25,50$ & $6196634 €$ & $5531781 €$ & $2655656 €$ & $959896 €$ \\
\hline $25,50,75$ & $6249443 €$ & $5571100 €$ & $2650794 €$ & $959896 €$ \\
\hline $75,90,99$ & $6408734 €$ & $5660055 €$ & $2643676 €$ & $959896 €$ \\
\hline
\end{tabular}

\subsection{Educational and Social Policies to Reduce Inequality}

In this section, educational and social policies to reduce life cycle earnings inequality are compared. Suppose for simplification that a society consists only of two countries with two individuals: the $10^{\text {th }}$ and the $90^{\text {th }}$ percentile. The policy maker wants to reduce the 90-10 inequality ratio from 3 (country A) to 1.89 (country B). To achieve this reduction in life time earnings inequality we will to compare three alternative policies. Policy 1 is a monetary transfer to the $10^{\text {th }}$ percentile taken from the $90^{\text {th }}$ percentile. Policy 2 is an exchange of educational inputs between the two members during their childhood and in policy 3 the government takes money from the $90^{\text {th }}$ percentile but instead of transferring it directly to the $10^{\text {th }}$ percentile it supplies additional education during childhood. In the following we thus compare these policies and discuss their relative superiority. 
It is first assumed that educational inequality arises from heterogeneous families. In country 2 the sum of the accumulated human capital of the $10^{\text {th }}$ and $90^{\text {th }}$ percentile is $1,651,937 €$ (see table 20 ). To reduce the $90-10$ ratio to a value of 1.89 the $10^{\text {th }}$ percentile needs to have a discounted lifetime income of $575,588 €$ and the $90^{\text {th }}$ percentile an income of 1,076,349 $€$. Table 28 compares the three different policies for the $10^{\text {th }}$ and $90^{\text {th }}$ percentile.

In policy 1 , wage inequality is reduced through a monetary transfer in period 18 . The $90^{\text {th }}$ percentile simply transfers $163,631 €$ to the $10^{\text {th }}$ percentile, thus reducing the $90-10$ ratio to 1.89 . In policy 2 , wage inequality is reduced by an educational exchange. The $90^{\text {th }}$ percentile gives up some education which the $10^{\text {th }}$ percentile receives. Table 28 illustrates this educational exchange for the preschool impulse and the primary school impulse described earlier. For a reduction in wage inequality it is sufficient for the $90^{\text {th }}$ percentile to transfer 0.131 educational units. Recall that one educational unit was defined as one year of schooling.

The reduction in the discounted lifetime income of the $90^{\text {th }}$ percentile is smaller in this case than in the one caused by the monetary transfer in policy 1 . Thus, a very early educational transfer can be a Pareto improvement compared to a direct monetary transfer in period 18. However, an educational transfer after period 6 (e.g. a transfer of primary school units) leads to a loss in discounted lifetime earnings for the $90^{\text {th }}$ percentile which exceeds the amount of money this person would have paid in a direct transfer. Compared to earlier periods, the skill level of the $90^{\text {th }}$ percentile in later periods is significantly higher relative to the $10^{\text {th }}$ percentile and skill complementary causes skill investments for the $90^{\text {th }}$ percentile to be much more productive as well. Thus, unlike an exchange of education in early childhood an exchange during middle to late childhood will be inefficient.

Policy 3 gives the $10^{\text {th }}$ percentile an educational transfer as well, but instead of redistributing education from the $90^{\text {th }}$ to the $10^{\text {th }}$ percentile, the government takes money from the $90^{\text {th }}$ percentile in period 18 . In this policy, a debt is made from the capital market in order to buy education for the $10^{\text {th }}$ percentile and later on, in period 18 , the money is demanded back from the $90^{\text {th }}$ percentile. According to table 21, policy 3 is a clear Pareto improvement as long as the educational impulse for the $10^{\text {th }}$ percentile is bought in preschool or in tertiary and secondary school.

However, sending the $10^{\text {th }}$ percentile student to university for achieving a compensation in wage inequality is not efficient because at that age, the learning multiplier and skill complementary are already too small and additional educational investments have only a negligible effect. To sum up, the best strategy for reducing inequality is to buy education for the $10^{\text {th }}$ percentile at a very young age and let the $90^{\text {th }}$ percentile pay the costs in later periods. 
Table 28: Comparing three different policies to reduce inequality (heterogeneous families)

\begin{tabular}{|c|c|c|c|c|}
\hline \multicolumn{5}{|c|}{$10^{\text {th }}$ percentile } \\
\hline Policy & Period of Policy & $\begin{array}{c}\text { Educational } \\
\text { transfer }\end{array}$ & $\begin{array}{c}\text { Monetary trans- } \\
\text { fer }\end{array}$ & $\begin{array}{l}\text { Change in dis- } \\
\text { counted lifetime } \\
\text { earnings }\end{array}$ \\
\hline Policy 1 & 18 & 0 & $+163,631 €$ & $+163,631 €$ \\
\hline \multirow[t]{2}{*}{ Policy 2} & 0 until 5 & +0.131 & 0 & $+163,631 €$ \\
\hline & 6 until 12 & +0.2334 & 0 & $+163,631 €$ \\
\hline \multirow{4}{*}{ Policy 3} & 0 until 5 & +0.131 & 0 & $+163,631 €$ \\
\hline & 6 until 11 & +0.2334 & 0 & $+163,631 €$ \\
\hline & 12 until 17 & +1.32 & 0 & $+163,631 €$ \\
\hline & 18 until 21 & +28.6 & 0 & $+163,631 €$ \\
\hline \multicolumn{5}{|c|}{$90^{\text {th }}$ percentile } \\
\hline Policy 1 & 18 & 0 & $-163,631 €$ & $-163,631 €$ \\
\hline \multirow[t]{2}{*}{ Policy 2} & 0 until 5 & -0.131 & 0 & $-162,840 €$ \\
\hline & 6 until 12 & -0.2334 & 0 & $-229,040 €$ \\
\hline \multirow{4}{*}{ Policy 3} & 18 & 0 & $-6015 €$ & $-6,015 €$ \\
\hline & 18 & 0 & $-9517 €$ & $-9,517 €$ \\
\hline & 18 & 0 & $-47792 €$ & $-47,792 €$ \\
\hline & 18 & 0 & $-612810 €$ & $-612,810 €$ \\
\hline
\end{tabular}

If skill heterogeneity arises from giftedness, the human capital profiles are different. Now a monetary transfer from the $90^{\text {th }}$ to the $10^{\text {th }}$ percentile of $167,465 €$ in period 18 is required to reduce inequality from 3 to 1.89 . The value differs slightly because heterogeneous giftedness produces different profiles of human capital across life. Table 29 compares the effects of the three policies described above for the scenario with heterogeneous giftedness. Policy 2, an exchange of education, is impossible since the amount of education required for the $10^{\text {th }}$ percentile in order to reduce inequality to the desired level is larger than the education the $90^{\text {th }}$ percentile receives.

Therefore, again policy 3 is the Pareto optimal strategy for reducing inequality. However, this policy is only Pareto dominant compared to direct redistribution as long as education for the $10^{\text {th }}$ percentile is provided in preschool or primary school education. The reason for this is that the ability of the $10^{\text {th }}$ percentile to use education is rather low. Therefore, the best strategy for reducing inequality is to buy edu- 
cation for the 10th percentile at a very young age and let the 90th percentile pay the costs in a later period.

Table 29: Comparing three different policies to reduce inequality (heterogeneous giftedness)

\begin{tabular}{|c|c|c|c|c|}
\hline \multicolumn{5}{|c|}{$\mathbf{1 0 ^ { \text { th } } \text { percentile }}$} \\
\hline Policy & Period of Policy & $\begin{array}{c}\text { Educational } \\
\text { transfer }\end{array}$ & $\begin{array}{c}\text { Monetary trans- } \\
\text { fer }\end{array}$ & $\begin{array}{c}\text { Change in dis- } \\
\text { counted lifetime } \\
\text { earnings }\end{array}$ \\
\hline Policy 1 & 18 & 0 & $+167,465 €$ & $+167,465 €$ \\
\hline Policy 2 & 0 until 5 & +0.64 & 0 & $+167,465 €$ \\
\hline \multirow{3}{*}{ Policy 3 } & 0 until 5 & +0.64 & 0 & $+167,465 €$ \\
\cline { 2 - 6 } & 6 until 11 & +1.19 & 0 & $+167,465 €$ \\
\cline { 2 - 6 } & 12 until 17 & +7.26 & 0 & $+167,465 €$ \\
\cline { 2 - 6 } & 18 until 21 & +130 & 0 & $+167,465 €$ \\
\hline Policy 1 & 18 & 0 & $-167,465 €$ & $-163,631 €$ \\
\hline Policy 2 & 0 until 5 & Not possible & 0 & Not possible \\
\hline \multirow{3}{*}{ Policy 3 } & 18 & 0 & $-29,387 €$ & $-29,387 €$ \\
\cline { 2 - 6 } & 18 & 0 & $-48,520 €$ & $-48,520 €$ \\
\cline { 2 - 6 } & 18 & 0 & $-262,853 €$ & $-262,853 €$ \\
\cline { 2 - 6 } & 18 & 0 & $-2,782,635 €$ & $-2,782,635 €$ \\
\hline
\end{tabular}

\section{Concluding Remarks}

In this study, we try to connect the economic literature on human capital formation with the biological and psychological literature on early childhood development and self-regulation across the life-span. Our basic framework for assessing the distribution of age-specific returns to investment in skills is an elaboration of the model of skill formation from Cunha, Heckman et al. (2006) over the life cycle. We illustrate the cumulative and synergetic nature of skill formation in a life cycle framework where learning abilities differ with respect to age and may differ between individuals and where individuals face heterogeneous environments. The formation of cognitive and self-regulatory skills is modelled by two equations of skill formation over the life cycle which are flexible enough for studying differences in synergy and interdependence in the formation of skills. Student achievement scores and human 
capital are modelled explicitly as a function of cognitive and self-regulatory skills. Institutional aspects of labour markets which may shape the distribution of human capital are taken into account in the simulation model.

The impact of age-dependent educational investment polices which aim at enhancing individual skills are evaluated in terms of their longer run multiplier effects. Individual educational choices are investigated for tertiary investments to maximize human capital, while for preschool, primary and secondary education the impact of different investment strategies are assessed without a particular model of choice. Various age- and skill-specific educational policies are appreciated with respect to individual returns to education, with respect to the overall accumulated human capital of the population of individuals and its distribution between the members of society. The parameters of the simulation model are adjusted in a way such that the formation of intelligence and self-regulation across the life span in our population of seven individuals reproduces facts and stylized facts from the development of the cognitive and self-regulatory skills, the student reading achievement scores from PISA 2000 and the inequality of wages in Germany in 2004, among others.

Our findings are in line with the interpretation of skill formation in Cunha, Heckman et al. (2006) and illustrate further the role of different investment strategies for example in self-regulatory skills. Skills beget skills and early investment has the highest returns to education. If our society of seven individuals wants to maximize the sum of the additional human capital formed by limited additional resources for investments in education, the best strategy is to either invest in students from a bright environment or with bright learning abilities. If the goal is the maximization of the relative returns to each individual, limited resources for additional educational investments should be directed to the most disadvantaged first in a world where the reason of heterogeneity is the environment. If heterogeneity stems form individual giftedness investments should again be directed to the most gifted individuals first.

Differences in individual giftedness thus have a higher impact on inequality than differences stemming from the environment. This is a result of the basic properties of the technology of skill formation, of self-productivity and of direct complementarities. Obviously, these findings have important policy implications. If the source of heterogeneity stems from varying individual abilities of transforming educational inputs into new additional skills instead of socio-economic heterogeneity of families, compensating policies directed, for instance, to equity goals need much more resources to be successful. A reasonable strategy for fostering human capital is to supply children with symmetric impulses into cognitive and self-regulatory skills until they reach adolescence. In adult age, however, more investments should be directed to improve self-regulatory skills. In a model variant it is illustrated that infancy might be even more critical for acquiring self-regulatory compared to cogni- 
tive skills. In this model variant skill formation in early childhood becomes even more important for shaping human capital over the life cycle.

A further analysis indicates that if it is not possible, for whatever reasons, to invest in early childhood, an increase in life expectancy seems to enhance returns of tertiary education specifically for students from disadvantaged environments. The relative gains from tertiary instead of primary additional education seem to be the higher the longer life expectancy lasts. The incentives to attend a tertiary education are the largest for gifted individuals from favourable environments in countries where the labour market leads to a high wage inequality. High labour market inequality generally increases the returns to education. If labour market inequality is too small, the benefit for attending a tertiary education can turn negative.

Our simulation based evidence contributes to the understanding of the skill multiplier and the shaping role early childhood has for human capital formation, growth and inequality. This is done in a synthetic, controlled world. Even though we tried to adjust the model world in a way that it hopefully captures some aspects of human capital in Germany, we regard our approach only as a first illustration. In future research, improved longitudinal and cross-section data, both experimental and nonexperimental, could be collected to upgrade the empirical understanding of the cumulative and synergetic nature of skill formation and the way families, schools and policies shape the future workforce.

\section{References}

Achtziger, A. and P. Gollwitzer (2006), Motivation und Volition im Handlungsverlauf. In J. Heckhausen, H. Heckhausen (Hrsg.), Motivation und Handeln. Berlin: Springer Verlag.

Ainslie, G. (2001), The Breakdown of Will. Cambridge: Cambridge University Press.

Armor, D. J. (2003). Maximizing intelligence. New Brunswick: Transaction Publishers.

Ashton, M. C. and K. Lee (2001), A Theoretical Basis for the Major Dimensions of Personality, European Journal of Personality (15), 327-353.

Ashton, M. C. and S. V. Paunonen (2001), Big Five Predictors of Academic Achievement, Journal of Research in Personality (35), 78-90.

Atkinson, A. B. (1970), On the measurement of inequality, Journal of Economic Theory 2 (3), 244-263. 
Autor, D., L. Katz and M. Kearney (2006), The Polarisation of the U.S. Labour Market, NBER Working Paper 11986.

Barnett, S. W. (1992), Benefits of Compensatory Preschool Education, Journal of Human Resources 27 (2), 279-312.

Belfield, C. R., M. Nores, S. Barnett and L. Schweinhardt (2006): The High/Scope Perry Preschool Program - Cost-Benefit-Analysis Using Data from the Age-40 Followup, The Journal of Human Resources 41(1), 162-190.

Belsky, J. (2001): Developmental Risks (Still) Associated with Early Child Care. Journal of Child Psychology and Psychiatry 42, 845-859.

Benabou, R.J.M. and J. Tirole (2004), Willpower and Personal Rules, Journal of Political Economy 112 (4), 848-887.

Black, S. E., P. J. Devereux, K. Salvanes (2005), From the Cradle to the Labor Market? The Effect of Birth Weight on Adult Outcomes, NBER Working Paper, 11796.

Blanden, J., L. Macmillan and P. Gregg (2006), 'Explaining Intergenerational Mobility: Non-cognitive skills, ability and education' Centre for the Economics of Education Discussion Paper, forthcoming.

Blundell R., L. Pistaferri, I. Preston (2005), Consumption Inequality and Partial Insurance, Mimeo, University College London.

Card, D. (2001): Estimating the Returns to Schooling: Progress on Some Persistent Econometric Problems, Econometrica, 69, 1127-1160.

Carneiro, P. and J. J. Heckman (2003), Human Capital Policy, in J.J. Heckman, A.B. Krueger und B.M. Friedman (Hrsg.): Inequality in America: What role for human capital policies?, Cambridge, MA, MIT Press.

Caspi, A., B. W. Roberts, R. L. Shiner (2005), Personality Development: Stability and change, Annual Review of Psychology 56, 453-484.

Chasteen, A.L., D. C. Park and N. Schwarz (2001), Implementation intentions and facilitation of prospective memory, Psychological Science, 12(6), 457-461.

Chesnokova, T. and K. Krishna (2006), Skill Acquisition, Credit Constraints, and Trade, NBER Working Paper 12411.

Courchesne, E., H.J. Chisum, J. Townsend, A. Cowles, J. Covington, B. Egaas, M. Harwood, Stuart Hinds und G.A. Press (2000), Normal Brain Development and Aging: Quantitative Analysis at in Vivo MR Imaging in Healthy Volunteers, Radiology, 216, 672-682.

Cunha, F. and J. J. Heckman (2007), The Technology of Skill Formation. The American Economic Review. 
Cunha, F., J. J. Heckman, L. Lochner and D. V. Masterov (2006), Interpreting the Evidence on Life Cycle Skill Formation, in: E.A. Hanushek und F. Welsch (eds.) Handbook of the Economics of Education, Amsterdam: North-Holland.

Currie, J. and E. Moretti (2003), Mother's Education and the Intergenerational Transmission of Human Capital: Evidence from College Openings, The Quarterly Journal of Economics 118 (4), 1495-1532.

Currie, J. and D. Thomas (1995): Does Head Start Make a Difference? The American Economic Review 85 (3), 341-364.

Dickens, W.T., I. Sawhill and J. Tebbs, The Effects of Investing in Early Education on Economic Growth, Brookings Working Paper, The Brookings Institution, 2006.

Dustmann, C. (2004), Parental Background, Secondary School Track Choice, and Wages, Oxford Economic Papers 56, 209-230.

Elliott, A. J., \& Dweck, C. S. (2005), Handbook of competence motivation, New York, The Guilford Press.

Ericson, E. (1963). Childhood and society (2nd ed.). New York: Norton.

Flossmann, A. and W. Pohlmeier (2006), Causal Returns to Education: A Survey on Empirical Evidence for Germany, Jahrbücher für Nationalökonomie und Statistik 226 (1), 1-23.

Franz, W. (2006), Arbeitsmarktökonomik (6. ed.), Springer.

Flynn, J. R. (1987). Massive IQ gains in 14 nations: What IQ tests really measure. Psychological Bulletin, 101, 171-191.

Gebel, M. and F. Pfeiffer (2007), Educational Expansion and its Heterogeneous returns for Wage Workers, Manuscript, Mannheim.

Gernandt, J. and F. Pfeiffer (2006), Rising Wage Inequality in Germany, ZEWDiscussion Paper 06-19.

Heckman, J.J., J. Stixrud and S. Urzua (2006), The Effects of Cognitive and Noncognitive Abilities on Labor Market Outcomes and Social Behavior , Journal of Labor Economics 24, 411-482.

Heckhausen, J. and H. Heckhausen (2006), Motivation und Entwicklung. In J. Heckhausen, H. Heckhausen, Motivation und Handeln. Berlin: Springer Verlag, 393-454.

Ho, K.C., Roessmann, U., Straumfjord, J.V., \& Monroe, G. (1980). Analysis of brain weight, Archives of Pathology and Laboratory Medicine, 104, 635-645.

Horwood, L.J. and D. M. Fergusson (1998), Breastfeeding and Later Cognitive and Academic Outcomes, Pediatrics, 101 (1). 
Jochmann, M. and W. Pohlmeier (2004), Der kausale Effekt von Bildungsinvestitionen, Bildung, Schriftenreihe des wirtschaftswissenschaftlichen Seminars Ottobeuren, W. Franz, H. J. Ramser, M. Stadler, Tübingen: Mohr Siebeck, 1-24.

Kaufman A.S., J.C. Kaufman, T.-H. Chen and N L. Kaufman (1996), Differences on Six Horn Abilities for 14 Age Groups Between 15-16 and 75-94 Years, Psychological Assessment 8 (2), 161-171.

Kliegel, M., C. Stork, M. Martin, G. Ramuschkat and D. Zimprich (2003), Komplexe prospektive Gedächtnisleistung im Alter: Der Einfluss von Aufgabensalienz und Intentionsplanung, Zeitschrift für Entwicklungspsychologie und Pädagogische Psychologie 35(4), 212-220.

Kliegel, M. and T. Jäger (2006), Can the Prospective and Retrospective Memory Questionnaire (PRMQ) predict actual prospective memory performance? , Current Psychology: Developmental, Learning, Personality, Social 25(3), 182-191.

Konsortium Bildungsberichterstattung (2006), Zur langfristigen Sicherstellung der Datenbasis für die Bildungsberichtserstattung, Frankfurt a. M..

Knudsen, E. J., J. J. Heckman, J. L. Cameron and J. P. Shonkoff (2006), Economic, Neurobiological and Behavioral Perspectives on Building America's Future Workforce, IZA Discussion Paper 2190.

Laucht, M. (2005), Die langfristigen Folgen früherer Entwicklungsrisiken: Ergebnisse der Mannheimer Längsschnittsstudie zu Risiko- und Schutzfaktoren, in Arnoldy, P. und Traub, B. (Hrsg.) Sprachentwicklungsstörungen früh erkennen und behandeln. Karlsruhe: Loeper, 169-183.

Ludwig, V. and F. Pfeiffer (2006), Abschreibungsraten allgemeiner und beruflicher Ausbildungsinhalte. Empirische Evidenz auf Basis subjektiver Einschätzungen, Jahrbücher für Nationalökonomie und Statistik, 226 (3), 260-284.

Magnusson, K. A., C.J. Ruhm and J. Waldfogel (2005): Does Pre-Kindergarten Improve School Preparation and Performance, NBER Working Paper No. W10452.

OECD (2000) PISA 2000 Database, OECD Paris.

OECD (2006a), Labour Force Statistics, OECD Paris.

OECD (2006b), Education at a Glance, OECD Paris.

Oerter, R. and L. Montada (2002), Entwicklungspsychologie, 5. Auflage, Weinheim.

Oreopoulos, P. (2006), Estimating Average and Local Average Treatment Effects of Education When Compulsory Schooling Laws Really Matter, American Economic Review 96, 152-175.

Pascalis, O., L.S. Scott, D.J. Kelly, R.W. Shannon, E. Nicholson, M. Coleman and C.A. Nelson (2005), Plasticity of face processing in infancy, Proceedings of the National Academy of Sciences of the United States of America 102 (14), 52975300 . 
Pfeiffer, F. (2000), Aufwand und Ertrag: Daten und Fakten zur Bildung in Deutschland und in Europa, K. Morath, Rohstoff Bildung, Bad Homburg, 11-26.

Phillips, D. and G. Adams (2001): Child Care and Our Youngest Children, The Future of Children 11(1), 34-51.

Roberts B. W., R. W. Robins, A. Caspi and K. Trzesniewski (2003), Personality trait development in adulthood, Handbook of the Life Course, J. Mortimer und M. Shanahan, New York, 579-598.

Rubinstein, Y. and Y. Weiss (2006). Post-school earnings: Search versus human capital, Handbook of the Economics of Education, Chapter 1, E. Hanushek and F. Welch, Amsterdam: North-Holland.

Rushton, J.P. and C. D. Ankey (1996), Brain size and cognitive ability: Correlations with age, sex social class and arid race, Psychomonic Bulletin \& Review 3, 2136.

Schultheiss, O. C. (2006), Needs, in: J. H. Greenhouse \& G. A. Callanan, Encyclopedia of career development (1), 532-535, Thousand Oaks, CA: Sage.

Sen, A. and J. Foster (1997), On Economic Inequality, Expanded Edition, Clarendon Press.

Spangler, William D. (1992), Validity of questionnaire and TAT measures of need for achievement: Two meta-analyses, Psychological Bulletin 112: 140-154.

Statistical Yearbook for the Federal Republic of Germany (2006), Statistisches Bundesamt, Wiesbaden.

Sugawa, M., H. Coper, G. Schulze, I. Yamashina, R. Krause and A. Dencher (1996), Impaired Plasticity of Neurons in Aging, Biochemical, Biophysical, and Behavioral Studies, Annals of the New York Academy of Sciences 786 (1), 274-282.

Votruba-Drzal, E., R. L. Coley and P. L. Chase-Lansdale (2004): Child care and low-income children's development - Direct and moderated effects. Child Development 75(1), 296-312.

Weinert, F. E. (2001), Vergleichende Leistungsmessung in Schulen - eine umstrittene Selbstverständlichkeit, Leistungsmessungen in Schulen, Weinert, F. E., Weinheim, Basel, 17-31.

West, R. (2005), The Neural Basis of Age-Related Declines in Prospective Memory, in: A Cabeza, R.,L. Nyberg, D. Park, Cognitive neuroscience of aging: Linking cognitive and cerebral aging, 246-264. 